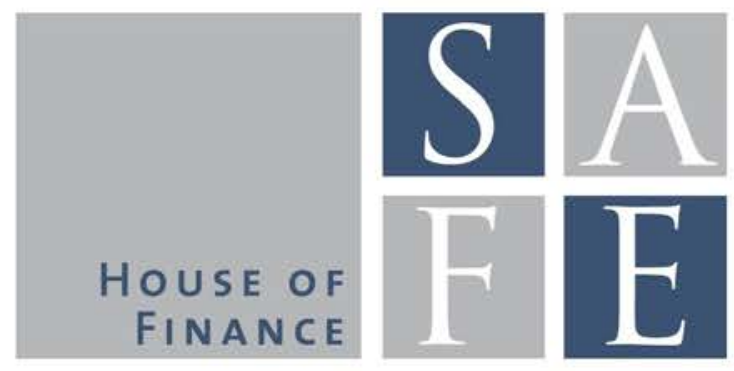

WORKING PAPER SERIES

Daniel Harenberg

\title{
Asset Pricing in OLG Economies With Borrowing Constraints and Idiosyncratic Income Risk
}

SAFE Working Paper No. 229

SAFE I Sustainable Architecture for Finance in Europe A cooperation of the Center for Financial Studies and Goethe University Frankfurt 


\title{
Asset Pricing in OLG Economies With Borrowing Constraints and Idiosyncratic Income Risk*
}

\author{
Daniel Harenberg ${ }^{\dagger}$ \\ ETH Zurich
}

September 17, 2018

\begin{abstract}
This paper analyzes how the combination of borrowing constraints and idiosyncratic risk affects the equity premium in an overlapping generations economy. I find that introducing a zero-borrowing constraint in an economy without idiosyncratic risk increases the equity premium by 70 percent, which means that the mechanism described in Constantinides, Donaldson, and Mehra (2002) is dampened because of the large number of generations and production. With social security the effect of the zero-borrowing constraint is a lot weaker. More surprisingly, when I introduce idiosyncratic labor income risk in an economy without a zero-borrowing constraint, the equity premium increases by 50 percent, even though the income shocks are independent of aggregate risk and are not permanent. The reason is that idiosyncratic risk makes the endogenous natural borrowing limits much tighter, so that they have a similar effect to an exogenously imposed zero-borrowing constraint. This intuition is confirmed when I add idiosyncratic risk in an economy with a zero-borrowing constraint: neither the equity premium nor the Sharpe ratio change, because the zero-borrowing constraint is already tighter than the natural borrowing limits that result when idiosyncratic risk is added.
\end{abstract}

JEL classification: G12; D91

Keywords: equity premium; idiosyncratic risk; aggregate risk; lifecycle

${ }^{*}$ I thank Johannes Brumm, Tom Krebs, Dirk Krueger, Felix Kubler, and Alexander Ludwig for helpful discussions. I gratefully acknowledge support of the German National Research Foundation (SFB 884), the Swiss Re Foundation, and the ETH Zurich Foundation.

${ }^{\dagger}$ Chair of Integrative Risk Management and Economics, ETH Zürich; dharenberg@ethz.ch. 


\section{Introduction}

Asset prices are subject to large fluctuations that directly change a household's wealth. To what extent the fluctuations translate into consumption and welfare depends on the extent to which households can insure against them. The degree of insurance in turn is a main determinant for the average return that agents require to hold an asset. The study of asset prices, and the equity premium, is of continued interest, because it helps economists understand to what degree households are exposed to risks, to what degree they can insure against them, and what the mechanisms behind it are.

More specifically, much of the applied and theoretical literature studies under what circumstances agents can or can't efficiently self-insure when markets are incomplete. Two forms of incompleteness that have received much attention are missing insurance markets for labor income risk and borrowing constraints. In standard economies with infinitely-lived households, they typically do not affect asset prices much, implying that consumers achieve a large degree of self-insurance. For life-cycle economies, on the other hand, an exogenous borrowing constraint (Constantinides, Donaldson, and Mehra (2002), hereafter CDM) and idiosyncratic income risk (Storesletten, Telmer, and Yaron (2007)) can each individually increase the equity premium by a potentially large amount.

This paper analyzes how the combination of these two forms of market incompleteness affect asset prices in an overlapping generations (OLG) economy. I first ask whether the large effect of the zero-borrowing constraint in CDM quantitatively survives in a richer environment with a large number of generations, production, and social security. These features should dampen their mechanism, but to what extent is an open, quantitative question. I then add idiosyncratic labor income risk that does not depend on aggregate risk. Given that the zero-borrowing constraint by itself can have a notable impact on the equity premium, the presence of idiosyncratic risk might or might not reinforce that.

The intuition for why the CDM mechanism should be mitigated by a large number of generations, production, and social security is straight-forward. CDM analyze a model with only three generations: the young, the middle-aged, and the retired. This limits intertemporal consumption smoothing, as any capital income shock to the retired directly translates into a consumption shock for a third of the population. Similarly, the introduction of a zero-borrowing constraint immediately affects a third of the population, 
namely the young. A larger number of generations means that agents can smooth the capital income shocks during retirement, and that a potentially much smaller fraction is affected by the borrowing constraint. Essentially, increasing the number of generations means that we approach the irrelevance results of infinitely-lived agent economies. Introducing production allows for an endogenous response of aggregate capital to shocks. As a consequence, the supply of assets is not fixed to an exogenous amount like in $\mathrm{CDM}$, which provides an additional margin along which the economy can respond to the introduction of a borrowing constraint. The third dampening force, social security, directly counteracts the high covariance of retirement consumption with stock returns, which is the crucial feature of the three-generations economy. The first question of the paper is by how much the three factors will mitigate the large increase in the equity premium that CDM find in their quantitative exercise.

The second question asks how the results change when households face uninsurable idiosyncratic labor income risk. Contrary to what might be expected, idiosyncratic risk in the present model increases the equity premium, even if there are no exogenous borrowing constraints. This is somewhat surprising given that the idiosyncratic risk is independent of aggregate risk. I show that this is due to tight natural borrowing limits which arise endogenously and act in a similar fashion as the exogenous borrowing limit. These natural borrowing limits arise because the household is not allowed to die in debt, which is similar to the No-Ponzi-scheme condition for infinitely-lived agents. Thus, when the exogenous borrowing constraint is introduced in an economy with idiosyncratic risk, the impact on the equity premium is not clear ex-ante. Given that both increase the equity premium individually, it could be that the combination of idiosyncratic risk and the exogenous borrowing constraint drive it even higher. On the other hand, one could offset the other, because they both prevent the young from holding stock.

To address the two questions, I build a large-scale OLG model with production and aggregate uncertainty. At every point in time, there are 65 generations, which differ due to a deterministic life-cycle profile for labor productivity. Households within a generation are identical ex-ante. In economies with idiosyncratic uncertainty there will be ex-post intragenerational heterogeneity caused by idiosyncratic shocks to labor income. Households choose how much to consume and how much to save in bonds and stock. The bond is one-period risk free, while the stock return depends on the realization of next period's aggregate shock. Trade is limited to these two assets by assumption and 
markets against aggregate risk are incomplete. Agents retire at the age of 65 and are not allowed to die in debt. In economies with a zero-borrowing constraint, agents cannot borrow in either asset. The social security system, if present, is a pure Pay-As-You-Go system with a fixed contribution rate. As an extension, I also look at an economy where the idiosyncratic labor income risk has a countercyclical variance (CCV).

There is a single consumption good produced by a representative firm with a CobbDouglas production function. The firm issues bonds and stock at an exogenously fixed debt-equity ratio to finance its capital requirements. The reason for modeling the firm's capital structure in this very simple way is that I want an exogenous supply of both assets so that there will be trade in both assets even with a zero-borrowing constraint. ${ }^{1}$ Each period, the production function is hit by a TFP shock which directly affects the aggregate wage and the marginal product of capital. The latter is also affected by stochastic depreciation, which is a well-known mechanism to increase the variance of asset returns.

The model is parameterized in a similar way as the related literature and calibrated to match key asset pricing statistics in the U. S., in particular the covariance of aggregate consumption growth with stock returns. The baseline economy, which has production and a large number of generations, but no idiosyncratic risk and no zero-borrowing constraint, features an equity premium of 1.6 percent. When the borrowing constraint is introduced, this increases to 2.7 percent. At the same time, the Sharpe ratio, which measures the market price per unit of risk, goes up from 0.14 to 0.23 . While, as expected, this is is less than the increase that Constantinides, Donaldson, and Mehra (2002) report, it is more than the typical finding with infinitely-lived agents. However, when social security is added, the equity premium drops again to 2.0 percent. Thus our intuition that social security directly counteracts the asset pricing effect of borrowing constraints is confirmed.

When I introduce idiosyncratic labor income risk in the economy without a zeroborrowing constraint, I find that the equity premium increases to 2.4 percent, slightly less than when the zero-borrowing limit is introduced. In view of the fact that the shocks are neither permanent nor correlated with the aggregate shock, this seems surprisingly

\footnotetext{
${ }^{1}$ An additional effect is that the stock return will be leveraged, which increases its mean and variance. The more standard case where the bond is in zero net supply and only the stock constitutes a claim on the firm's capital is nested for a debt-equity ratio of zero. Cf. e. g. Boldrin, Christiano, and Fisher (1995), or Croce (2010).
} 
much. $^{2}$ I elaborate on this by showing that the natural borrowing limits, which are implied by the requirement that agents can't die in debt, are tight and act in a similar manner to the exogenous zero-borrowing limit. This claim is further substantiated when I look at an economy with both a zero-borrowing constraint and idiosyncratic risk: here, the equity premium and the Sharpe ratio are exactly the same as in the economy with only the exogenous borrowing constraint (and without idiosyncratic risk). The reason is that the zero-borrowing constraint is tighter than the natural borrowing limit, so the latter is ineffective. Consequently, we get an irrelevance result like in the case with infinitely-lived agents.

Finally, I perform the same experiment for labor income risk with a countercyclical variance $(\mathrm{CCV})$. I find that the results are essentially the same as for idiosyncratic risk with a homoscedastic variance. This might seem like a stark difference to Storesletten, Telmer, and Yaron (2007). However, that paper and the companion papers do not explicitly analyze the difference between idiosyncratic risk with CCV and with a homoscedastic variance. One reason that $\mathrm{CCV}$ adds so little in the present setup is that the process does not contain a unit root, and the mapping of CCV to the aggregate state is different, as is detailed in the section 5.4 .

Related literature. The quantitative irrelevance of borrowing constraints and idiosyncratic risk in models with infinitely-lived agents has been documented by e. g. Lucas (1994), Telmer (1993), Heaton and Lucas (1996), and more recently Krusell, Mukoyama, and Smith (2011). ${ }^{3}$ Krueger and Lustig (2010) obtain analytical results for the irrelevance of idiosyncratic risk for asset pricing with general borrowing constraints that cover those that I consider. In contrast to their setup, the present model has production, aggregate shocks that are not i.i.d., and a productivity life-cycle.

Constantinides and Duffie (1996) show that if idiosyncratic income follows a unit root process with a countercyclical variance, then it can have a large impact on asset prices. Krebs and Wilson (2004) extend their results to an endogenous growth model with production, and Storesletten, Telmer, and Yaron (2007) add the life-cycle. Krusell, Mukoyama, and Smith (2011) provide analytical and quantitative results confirming a

\footnotetext{
${ }^{2}$ One table in Storesletten, Telmer, and Yaron (2008) seems to show something similar, but their numbers are inconclusive and they don't comment on it.

${ }^{3}$ In contrast, Krusell and Smith (1997) find a large effect of introducing borrowing constraints. This might be due to the zero net supply of the bond.
} 
large impact of $\mathrm{CCV}$ on the equity premium. Note that in the present paper, equilibria will not be autarkic.

Turning to OLG economies, Ríos-Rull (1994) and Ríos-Rull (1996) find that incompleteness of markets against aggregate risk do not matter much for asset prices and business cycles. Gomes and Michaelides (2008) have a very similar setup to the present one, but they focus on the impact of limited participation on the equity premium.

Finally, the present paper is related to the literature on endogenous borrowing limits. For the case without aggregate uncertainty, Aiyagari (1994) discusses the natural borrowing limit arising from a no-Ponzi-scheme condition. Magill and Quinzii (1994), Levine and Zame (1996), and Levine and Zame (2002) do this for economies with incomplete markets against aggregate risk. Their theoretical results are relevant for the present paper, but the approach here is a quantitative one similar to Aiyagari. Another strand of literature looks at endogenous borrowing limits arising from the possibility of default, or limited enforceability of debt contracts. Zhang (1997) and Alvarez and Jermann (2001) find that the asset pricing implications of such borrowing limits are large, which is very similar in spirit to the findings in the present paper. Alvarez and Jermann (2000) prove existence of competitive equilibrium in such economies, and Ábrahám and Carceles-Poveda (2010) extend the setup to include production and an infinite number of agents, making it closer to the present paper, but they focus on taxation.

The next section presents the model. Section three gives details on the computation and the implementation of the natural borrowing limits. Section four presents the calibration. In section five the results are discussed, and in section six I conclude.

\section{The Model}

\subsection{Demographics and Uncertainty}

Time is discrete and runs from $t=0, \ldots, \infty$. At the beginning of each period $t$, an aggregate shock $z_{t}$ hits the economy. For a given initial $z_{0}$, a date-event is uniquely identified by the history of shocks $z^{t}=\left(z_{0}, z_{1}, \ldots, z_{t}\right)$. The shocks $z_{t}$ follow a Markov chain with finite support $\mathcal{Z}$ and nonnegative transition matrix $\pi_{z}$. So $\pi_{z}\left(z_{t+1} \mid z_{t}\right)$ represents the probability of the shock next period given the current shock, and $\pi_{z}\left(z^{t} \mid z^{t_{0}}\right)$ represents 
the probability of reaching date-event $z^{t}$ from a given date-event $z^{t_{0}}$.

At every point in time $t$, the economy is populated by $J$ overlapping generations indexed by $j=1, \ldots, J$. Each generation consists of a continuum of households of unit mass. ${ }^{4}$ Agents within a cohort are ex-ante identical but receive an idiosyncratic shock $s_{j}$ each period so that there is (ex-post) intragenerational heterogeneity with respect to the history of idiosyncratic shocks $s^{j}$. Like the aggregate shock, $s_{j}$ follows a Markov chain with finite support $\mathcal{S}$ and strictly positive transition matrix $\pi_{s}$. The transition probabilities are $\pi_{s}\left(s_{j+1} \mid s_{j}\right)$ and the probability of a specific idiosyncratic shock history is $\pi_{s}\left(s^{j}\right)$. I assume that a Law of Large Numbers holds, so that $\pi_{s}\left(s^{j}\right)$ represents both the individual probability for $s^{j}$ as well as the fraction of the population with that shock history; the same obtains for the transition probabilities $\pi_{s}\left(s_{j+1} \mid s_{j}\right)$. Finally, $\pi_{s}\left(s_{j}\right)$ denotes the unconditional probability of shock $s_{j}$.

\subsection{Households}

At any date-event $z^{t}$, a household is fully characterized by their age $j$ and their history of idiosyncratic shocks $s^{j}$. Preferences over consumption $c$ are represented by a recursive utility function $U_{j}(c, \cdot)$ of the Epstein-Zin form (Epstein and Zin (1989), Kreps and Porteus (1978)):

$$
\begin{aligned}
U_{j}\left(c, s^{j}, z^{t}\right) & =\left(\left[c_{j}\left(s^{j}, z^{t}\right)\right]^{\frac{1-\theta}{\gamma}}\right. \\
+\beta & \left.\left(\sum_{z_{t+1}} \sum_{s_{j+1}} \pi_{z}\left(z_{t+1} \mid z_{t}\right) \pi_{s}\left(s_{j+1} \mid s_{j}\right)\left[U_{j+1}\left(c, s^{j+1}, z^{t+1}\right)\right]^{1-\theta}\right)^{\frac{1}{\gamma}}\right)^{\frac{\gamma}{1-\theta}} \\
U_{J}\left(c, s^{J}, z^{t}\right) & =c_{J}\left(s^{J}, z^{t}\right) \\
c & >0
\end{aligned}
$$

where $\beta$ is the discount factor and $\theta$ controls risk aversion. The parameter $\gamma$ is defined as $\gamma=\frac{1-\theta}{1-\frac{1}{\phi}}$ with $\phi$ denoting the elasticity of intertemporal substitution. The CRRA utility specification is nested for $\theta=\frac{1}{\phi}$ which gives $\gamma=1$.

Households inelastically supply one unit of labor until they retire at the fixed re-

\footnotetext{
${ }^{4}$ In contrast to the previous chapter, there is no population growth or survival risk.
} 
tirement age $j_{r}$. They are endowed with a deterministic life-cycle productivity profile $e_{j}$. Every period, each household receives an income shock $\eta$, which depends on his realization of $s_{j}$ and may also depend on the current aggregate shock $z_{t}$. Labor income $y_{j}\left(s_{j}, z^{t}\right)$ is then given as

$$
y_{j}\left(s_{j}, z^{t}\right)=w\left(z^{t}\right) e_{j} \eta\left(s_{j}, z_{t}\right)
$$

where $w\left(z^{t}\right)$ is the real, aggregate wage in terms of the consumption good at $z^{t}$. By construction, the unconditional expectation of idiosyncratic income shocks is equal to one, i.e. letting $\Pi\left(s_{t}\right)$ be the stationary distribution of $s_{t}$, we have that $\sum_{s_{t}} \Pi\left(s_{t}\right) \eta\left(s_{t}, z_{t}\right)=1$ for all $z_{t}$. The idiosyncratic income shock $\eta\left(s_{j}, z_{t}\right)$ is the only channel through which $s_{t}$ affects the household. Insurance markets against this risk are closed by assumption.

There are two assets that agents can trade to transfer wealth from one period to the next, called stocks and bonds. Since by assumption the cardinality of $\mathcal{Z}$ is greater than two, markets against aggregate risk are incomplete. Both the stock and the bond constitute a claim on the firm's capital in the following period. They only differ in their returns: the stock has a risky return $r_{\sigma}\left(z^{t+1}\right)$ that depends on the realization of the aggregate uncertainty in the following period, whereas the bond pays an interest rate $r_{b}\left(z^{t}\right)$ that is one period risk-free. Households buy amounts $\sigma_{j}\left(s^{j}, z^{t}\right)$ of stock and $b_{j}\left(s^{j}, z^{t}\right)$ of bonds by selling the consumption good to the firm. The firm transforms the consumption good into next period capital. The sequential budget constraint is standard:

$$
\begin{aligned}
c_{j}\left(s^{j}, z^{t}\right)+\sigma_{j}\left(s^{j}, z^{t}\right)+b_{j}\left(s^{j}, z^{t}\right) & =\left(1+r_{\sigma}\left(z^{t}\right)\right) \sigma_{j-1}\left(s^{j-1}, z^{t-1}\right) \\
& +\left(1+r_{b}\left(z^{t-1}\right)\right) b_{j-1}\left(s^{j-1}, z^{t-1}\right) \\
& +(1-\tau) y_{j}\left(s_{j}, z^{t}\right) I(j)+y_{s s}\left(z^{t}\right)(1-I(j)),
\end{aligned}
$$

where $\tau$ is a fixed social security contribution rate, $y_{s s}\left(z^{t}\right)$ is pension income from social security, and $I(j)$ is an indicator function which takes the value 1 if $j<j_{r}$ and 0 else (recall that $j_{r}$ is the retirement age and that the process for labor income $y_{j}\left(s_{j}, z^{t}\right)$ is given in eq. 2). All households are born with zero assets, i.e. $\sigma_{0}\left(s^{0}, z^{t}\right)=b_{0}\left(s^{0}, z^{t}\right)=0$.

In addition to the budget constraint, households face one of two borrowing constraints, which both are very common in the literature. The first constraint requires that households 
can not die with debt, or more precisely, with a negative net asset position:

$$
\sigma_{J}\left(s^{J}, z^{t}\right)+b_{J}\left(s^{J}, z^{t}\right) \geq 0 .
$$

This is a standard constraint to rule out Ponzi-schemes in economies with finite lifetimes. Together with the requirement of positive consumption $c>0 \forall z^{t}$, it implies a sequence of endogenous borrowing constraints on the net value the household can borrow at each date event. ${ }^{5}$ Somewhat loosely, we can say that the household cannot borrow more than the present value of his worst future income stream. The second constraint an exogenously imposed zero-borrowing limit:

$$
\begin{aligned}
& \sigma_{j}\left(s^{j}, z^{t}\right) \geq 0 \\
& b_{j}\left(s^{j}, z^{t}\right) \geq 0
\end{aligned}
$$

Households will face either the nonnegative bequest (NNB) constraint or the tighter zero-borrowing (ZB) constraint.

\subsection{Firms}

There is a representative firm that uses capital $K\left(z^{t}\right)$ and labor $L\left(z^{t}\right)$ to produce the consumption good $Y\left(z^{t}\right)$. The production technology is Cobb-Douglas with capital share $\alpha$ and deterministic, labor-augmenting productivity growth $\lambda$. At each date-event, it is subject to a multiplicative shock to total factor productivity $\zeta\left(z_{t}\right)$ which depends only on the current aggregate shock:

$$
Y\left(z^{t}\right)=\zeta\left(z_{t}\right) K\left(z^{t}\right)^{\alpha}\left((1+\lambda)^{t} L\left(z^{t}\right)\right)^{1-\alpha}
$$

Households purchase the produced goods to satisfy their consumption needs. Alternatively, the firm can use the goods to invest in capital. Assuming zero capital adjustment costs and a stochastic depreciation rate $\delta\left(z_{t}\right)$, the capital stock evolves according to:

$$
K\left(z^{t+1}\right)=I\left(z^{t}\right)+K\left(z^{t}\right)\left(1-\delta\left(z_{t}\right)\right)
$$

\footnotetext{
${ }^{5}$ Of course, we also need full enforceability of contracts, so that default is precluded.
} 
The firm finances its capital requirements $K\left(z^{t+1}\right)$ by issuing stock and bonds. Both one share of stock and a bond give the holder a claim on one unit of tomorrow's capital stock. The capital structure of the firm is exogenous and determined by a constant debt-equity ratio $\bar{d}$ :

$$
K\left(z^{t+1}\right)=\Sigma\left(z^{t+1}\right)+B\left(z^{t+1}\right)=\Sigma\left(z^{t+1}\right)(1+\bar{d})
$$

where $\Sigma$ and $B$ are the amount of stock and bond issued by the firm. ${ }^{6}$ The return on capital has to equal

$$
r\left(z^{t+1}\right) K\left(z^{t+1}\right)=r\left(z^{t+1}\right) \Sigma\left(z^{t+1}\right)(1+\bar{d}) .
$$

Out of this, bondholders receive

$$
r_{b}\left(z^{t}\right) B\left(z^{t+1}\right)=r_{b}\left(z^{t}\right) \bar{d} \Sigma\left(z^{t+1}\right)
$$

and stock holders receive the rest, which is

$$
r_{\sigma}\left(z^{t+1}\right) \Sigma\left(z^{t+1}\right)=r\left(z^{t+1}\right) \Sigma\left(z^{t+1}\right)(1+\bar{d})-r_{b}\left(z^{t}\right) \bar{d} \Sigma\left(z^{t+1}\right) .
$$

Consequently, the bond and stock returns can be calculated directly from the return on capital as

$$
\begin{aligned}
r_{b}\left(z^{t}\right) & =\frac{1}{\bar{d}} E\left[r\left(z^{t+1}\right)(1+\bar{d})-r_{\sigma}\left(z^{t+1}\right) \mid z^{t}\right] \\
r_{\sigma}\left(z^{t+1}\right) & =r\left(z^{t+1}\right)(1+\bar{d})-\bar{d} r_{b}\left(z^{t}\right)
\end{aligned}
$$

As one can see, the stock return is leveraged. This increases both its expected value as well as its variance. For $\bar{d}=0$ we are back to the standard case where the return on capital equals the return on the risky asset.

\footnotetext{
${ }^{6}$ See, for example, Boldrin, Christiano, and Fisher (1995) or Croce (2010) for modeling capital structure this way.
} 


\subsection{Social Security}

Social security is a pay-as-you-go system with a fixed contribution rate $\tau$ that is levied on labor income. Pension income $y_{s s}\left(z^{t}\right)$ adjusts to ensure that the social security budget is balanced in every date-event. By assumption $y_{s s}\left(z^{t}\right)$ does not depend on the idiosyncratic history, which means that every household receives the same pension income. ${ }^{7}$ The case $\tau=0.0$, i.e. an economy without a social security system, will be the baseline case.

\subsection{Equilibrium}

I will first define a competitive equilibrium, because it is economically intuitive and directly refers to the model as it has been set up. Also, we know that such equilibria exist. Then I will define the special case of a recursive competitive equilibrium, which is used in the quantitative experiments. There, I will restate all model elements in recursive form.

Definition 1. For an initial aggregate state $z_{0}$, an initial distribution $\left\{\Pi_{0}\left(s^{j}\right)\right\}_{j}$ and associated initial stock and bond positions $\left\{\sigma_{j}\left(s^{j}, z_{0}\right), b_{j}\left(s^{j}, z_{0}\right)\right\}_{j}$, a competitive general equilibrium consists of sequences for household choices $\left\{c_{j}\left(s^{j}, z^{t}\right), \sigma_{j}\left(s^{j}, z^{t}\right)\right.$, $\left.b_{j}\left(s^{j}, z^{t}\right)\right\}_{j}$, firm choices $\left\{K\left(z^{t}\right), L\left(z^{t}\right)\right\}$, social security settings $\left\{\tau, y_{s s}\left(z^{t}\right)\right\}$, factor prices $\left\{w\left(z^{t}\right), r\left(z^{t}\right)\right\}$, and asset returns $\left\{r_{b}\left(z^{t}\right), r_{\sigma}\left(z^{t}\right)\right\}$ such that for all $\left(s^{j}, z^{t}\right)$ :

a) given prices and returns, household choices solve the households' problem of maximizing (1) subject to (2), (3), and either (NNB) or (ZB)

b) factor prices and firm choices are related by

$$
\begin{aligned}
w\left(z^{t}\right) & =(1-\alpha)(1+\lambda)^{t} \zeta\left(z_{t}\right)\left(\frac{K\left(z^{t}\right)}{L\left(z^{t}\right)}\right)^{\alpha} \\
r\left(z^{t}\right) & =\alpha \zeta\left(z_{t}\right)\left(\frac{K\left(z^{t}\right)}{L\left(z^{t}\right)}\right)^{\alpha-1}-\delta\left(z_{t}\right)
\end{aligned}
$$

c) asset returns are given by (7) and (8)

\footnotetext{
${ }^{7}$ As discussed in the previous chapter, one can argue that this is a reasonable approximation to the U.S. pension system.
} 
d) the social security budget is balanced, i.e.

$$
\sum_{j=1}^{j_{r}-1} \sum_{s_{j}}(1-\tau) y_{j}\left(s_{j}, z^{t}\right) \pi_{s}\left(s_{j}\right)=\left(J-\left(j_{r}-1\right)\right) y_{s s}\left(z^{t}\right)
$$

e) all markets clear:

$$
\begin{aligned}
Y\left(z^{t}\right)+\left(1-\delta\left(z_{t}\right)\right) & K\left(z^{t}\right) \\
& =\sum_{j=1}^{J} \sum_{s^{j}} c_{j}\left(s^{j}, z^{t}\right) \pi_{s}\left(s^{j}\right)+K\left(z^{t+1}\right) \\
K\left(z^{t}\right) & =\sum_{j=1}^{J} \sum_{s^{j}}\left(\sigma_{j}\left(s^{j-1}, z^{t-1}\right)+b_{j}\left(s^{j-1}, z^{t-1}\right)\right) \pi_{s}\left(s^{j-1}\right) \\
\frac{1}{(1+\bar{d})} K\left(z^{t}\right) & =\sum_{j=1}^{J} \sum_{s^{j}} \sigma_{j}\left(s^{j-1}, z^{t-1}\right) \pi_{s}\left(s^{j-1}\right) \\
L\left(z^{t}\right) & =\sum_{j=1}^{j_{r}-1} e_{j}
\end{aligned}
$$

Recall that by the law of large numbers, $\pi_{s}\left(s^{j}\right)$ represents the fraction of of households with that specific idiosyncratic shock history, and that each generation has unit mass. The capital market clearing equation (13) shows that next period's capital is financed by both stocks and bonds, and the following stock market clearing equation (14) states that total stock is always a constant fraction of aggregate capital, with bonds making up the remainder. This follows from our assumption of a constant debt-equity-ratio $\bar{d}$.

While we know that such competitive equilibria exist, we generally can't compute them. ${ }^{8}$ To make the solution computationally feasible, the literature usually defines a recursive competitive equilibrium. I first de-trend the economy by dividing all aggregate and individual variables by the level of technology $(1+\lambda)^{t}$. Since in a recursive equilibrium all endogenous variables are functions of the current state, one needs to define a state space that is sufficient for solving the households' maximization problem.

\footnotetext{
${ }^{8}$ See Kubler and Polemarchakis (2004) for an existence proof in an OLG economy with stochastic production and a finite number of heterogeneous households. Miao (2006) considers the case of a continuum of infinitely-lived heterogeneous households subject to the zero-borrowing constraint zero borrowing (ZB), also with stochastic production. Alvarez and Jermann (2000) provide an existence proof for an economy with endogenous, state-dependent borrowing constraints that are similar in spirit to (NNB).
} 
I follow the applied literature and use the current asset distribution, together with current idiosyncratic and aggregate shocks as the state. ${ }^{9}$ Let the current probability distribution over current stock and bond holdings, current idiosyncratic shocks, and age be denoted by $\Phi .{ }^{10}$ The set of measures $\Phi$ is defined over $\mathcal{M}$, which is a family of subsets of $\{[\underline{\sigma}, \infty] \times[\underline{b}, \infty] \times \mathcal{S} \times \mathcal{J}\}$, where $\underline{\sigma}$ and $\underline{b}$ are implied by (NNB) or (ZB). In addition to $\Phi$, each household needs to know their own current idiosyncratic state $(\sigma, b, s)$ and the current aggregate shock $z$. Since a recursive equilibrium does not depend on the date-event, I drop the time index $t$, and use a prime for next period's variables.

Definition 2. A recursive competitive equilibrium consists of a distribution $\Phi$, measurable functions for household choices $\left\{c_{j}(\sigma, b, s ; \Phi, z), \sigma_{j}^{\prime}(\sigma, b, s ; \Phi, z), b_{j}^{\prime}(\sigma, b, s ; \Phi, z)\right.$ and an associated value function $U(\sigma, b, s ; \Phi, z)$, firm choices $\{K(\Phi, z), L(\Phi, z)\}$, social security settings $\left\{\tau, y_{s s}(\Phi, z)\right\}$, factor prices $\{w(\Phi, z), r(\Phi, z)\}$, asset returns $\left\{r_{b}(\Phi)\right.$, $\left.r_{\sigma}(\Phi, z)\right\}$, and a law of motion $H(\Phi, z)$ such that:

a) given functions for prices and returns and the law of motion, the households' policy functions $\left\{c_{j}(\sigma, b, s ; \Phi, z), \sigma_{j}^{\prime}(\sigma, b, s ; \Phi, z), b_{j}^{\prime}(\sigma, b, s ; \Phi, z)\right.$ solve

$$
\begin{aligned}
& \max _{c>0, \sigma^{\prime}, b^{\prime}} U_{j}(\sigma, b, s ; \Phi, z) \\
& =\left\{\begin{aligned}
\left(c^{\frac{1-\theta}{\gamma}}+\tilde{\beta}\left(\sum_{z^{\prime}} \sum_{s^{\prime}} \pi_{z}\left(z^{\prime} \mid z\right) \pi_{s}\left(s^{\prime} \mid s\right) U_{j+1}^{1-\theta}\left(\sigma^{\prime}, b^{\prime}, s^{\prime} ; H(\Phi, z), z^{\prime}\right)\right)^{\frac{1}{\gamma}}\right)^{\frac{\gamma}{1-\theta}} \\
\text { if } j=J
\end{aligned}\right. \\
& \text { s.t. } \quad \begin{aligned}
c+\sigma^{\prime}+b^{\prime} & =\left(1+r_{\sigma}(\Phi, z)\right) \sigma+\left(1+r_{b}(\Phi)\right) b \\
+ & (1-\tau) y_{j}(s, \Phi, z) I(j)+y_{s s}(\Phi, z)(1-I(j)) \\
y_{j}(s, \Phi, z) & =w(\Phi, z) e_{j} \eta(s, z), \\
\sigma^{\prime}+b^{\prime} & \geq 0 \quad \text { if } j=J .
\end{aligned}
\end{aligned}
$$

\footnotetext{
${ }^{9}$ See, e. g. Ríos-Rull (1996) or Krusell and Smith (1998). In general, only the existence of 'generalized Markov equilibria' can be proven, see e. g. Kubler and Polemarchakis (2004). However, Cao (2012) proves the existence of recursive equilibria with such a minimal state space consisting of the current distribution of wealth and shocks.

${ }^{10} \mathrm{We}$ need a distribution which is continuous over $(b, \sigma)$ because there is a continuum of agents in each generation. If there was a finite number of households, we could instead track each households' current asset holdings.
} 
b) functions for prices and for firm choices are related by

$$
\begin{aligned}
& w(\Phi, z)=(1-\alpha) \zeta(z)\left(\frac{K(\Phi)}{L(\Phi)}\right)^{\alpha} \\
& r(\Phi, z)=\alpha \zeta(z)\left(\frac{K(\Phi)}{L(\Phi)}\right)^{\alpha-1}-\delta(z)
\end{aligned}
$$

c) functions for asset returns are given by

$$
\begin{aligned}
r_{b}(\Phi) & =\frac{1}{\bar{d}} E\left[r(\Phi, z)(1+\bar{d})-r_{\sigma}(\Phi, z) \mid z\right] \\
r_{\sigma}(\Phi, z) & =r(\Phi, z)(1+\bar{d})-\bar{d} r_{b}(\Phi)
\end{aligned}
$$

d) the function for social security settings ensures a balanced budget, i.e.

$$
\sum_{j=1}^{j_{r}-1} \sum_{s}(1-\tau) y_{j}(s, \Phi, z) \pi_{s}(s)=\left(J-\left(j_{r}-1\right)\right) y_{s s}(\Phi, z)
$$

e) all markets clear:

$$
\begin{aligned}
\zeta(z) K(\Phi)^{\alpha}(L(\Phi))^{1-\alpha}+(1-\delta(z)) K(\Phi) & \\
& =\sum_{j=1}^{J} \sum_{s} \int_{b} \int_{\sigma} c_{j}(\sigma, b, s ; \Phi, z) \Phi(\sigma, b, s, j) d b d \sigma+K(H(\Phi, z)) \\
K(\Phi) & =\sum_{j=1}^{J} \sum_{s} \int_{b} \int_{\sigma}(\sigma+b) \Phi(\sigma, b, s, j) d b d \sigma \\
\frac{K(\Phi)}{(1+\bar{d})} & =\sum_{j=1}^{J} \sum_{s} \int_{b} \int_{\sigma} \sigma \Phi(\sigma, b, s, j) d b d \sigma \\
L(\Phi) & =\sum_{j=1}^{j_{r}-1} e_{j}
\end{aligned}
$$

f) the law of motion $H$ is generated by the policy functions and the Markov transition matrix $\pi_{s}$ so that

$$
\Phi^{\prime}=H(\Phi, z)
$$


In the households' utility, $\tilde{\beta}=\beta(1+\lambda)^{\frac{1-\theta}{\gamma}}$ because of the normalization with the deterministic trend. As before, agents are born with zero assets, so that for $j=1, \sigma=0$ and $b=0$. The condition of nonnegative bequests in the recursive equilibrium is (NNB'); recall that either this or the stricter zero-borrowing constraint (ZB') will be imposed:

$$
\begin{aligned}
& \sigma_{j}^{\prime}(\sigma, b, s ; \Phi, z) \geq 0 \\
& b_{j}^{\prime}(\sigma, b, s ; \Phi, z) \geq 0
\end{aligned}
$$

By the law of large numbers, unconditional probability of receiving shock $s, \pi_{s}(s)$, is equal to the corresponding marginal distribution of $\Phi$, i.e. $\pi_{s}(s)=\int_{b} \int_{\sigma} \Phi(\sigma, b, s, j) d b d \sigma$, $\forall s, j$. This equilibrium is not stationary in the sense that $\Phi$ is not time-invariant.

\section{Computation}

\subsection{Computational Solution}

The computational procedure is the same as in the previous chapter. I restate the main elements with a focus on the application at hand, because the model notation differs. I compute the recursive equilibrium using global solution methods. ${ }^{11}$ I follow the recent, applied literature and use the Krusell and Smith (1998) procedure to approximate the distribution $\Phi$ with a finite number of moments, and to approximate the law of motion $H(\cdot)$ by a specific functional form $\hat{H} .^{12}$ Intuitively, households need to know next period's prices $w^{\prime}, r_{\sigma}^{\prime}, r_{b}^{\prime}$ in order to solve their maximization problem, and the approximate law of motion $\hat{H}(\cdot)$ should enable them to forecast these prices. Let the expected equity premium be $\mu(\Phi, z)=E\left[r_{\sigma}\left(H(\Phi, z), z^{\prime}\right)-r_{b}(H(\Phi, z)) \mid z\right]$. The laws of motion households use are linear forecasts of next period's capital $K^{\prime}$ and next periods

\footnotetext{
${ }^{11}$ To be precise, all one can do is to approximate the recursive equilibrium numerically. So in general we compute $\epsilon$-equilibria as defined by Kubler and Polemarchakis (2004). These are known to exist.

${ }^{12}$ Krueger and Kubler (2004) show that this method can yield a bad approximation if the number of generations $J$ is not large. However, in a model with a large number of generations, like the present one, the method should perform better, since the model is more similar to an infinite horizon model.
} 
expected equity premium $\mu^{\prime}$ :

$$
\begin{aligned}
\hat{K}^{\prime} & =\psi_{0}^{K}(z)+\psi_{1}^{K}(z) \ln (K)+\psi_{2}^{K}(z) \ln (K)^{2}, \\
\hat{\mu}^{\prime}\left(z^{\prime}\right) & =\psi_{0}^{\mu}\left(z^{\prime}\right)+\psi_{1}^{\mu}\left(z^{\prime}\right) \ln \left(\hat{K}^{\prime}\right)+\psi_{2}^{\mu}\left(z^{\prime}\right) \ln \left(\hat{K}^{\prime}\right)^{2},
\end{aligned}
$$

where $\{\psi(z)\}_{0,1,2}^{K, \mu}$ are state-contingent coefficients. By forecasting $K^{\prime}$ households can calculate tomorrow's marginal productivity of capital and labor. Combining this with a forecast of $\mu^{\prime}$ enables them to calculate the expected stock and bond returns. ${ }^{13}$ The approximate law of motion (16-17) is close to the ones employed by Gomes and Michaelides (2008) Storesletten, Telmer, and Yaron (2007), and Krusell and Smith (1997). Note that one $\mu^{\prime}$ is forecast for each $z^{\prime}$, and that the forecast depends on $\hat{K}^{\prime}$. This mirrors the true equity premium one period ahead $\mu^{\prime}\left(H(\Phi, z), z^{\prime}\right)$, which also depends on the the transition of $\Phi$ and on $z^{\prime}$.

The coefficients $\{\psi(z)\}_{0,1,2}^{K, \mu}$ are estimated from simulations. Like Gomes and Michaelides (2008), I simulate the economy for $T=5000$ periods and discard the first 500 to avoid the impact of initial values. The initial distribution and the aggregate grids are initialized with the help of a degenerate equilibrium, which I call 'mean-shock' equilibrium and describe in the appendix A.1.1. In each simulation period, I explicitly solve for the equity premium that clears bond and stock markets. While this is a timeconsuming step, it improves the regressions. I use the quasi-Newton method described in Ludwig (2007) to find the fixed-point of $\left(\{\psi(z)\}_{0,1,2}^{K, \mu}\right)_{i+1}=\Psi\left(\left(\{\psi(z)\}_{0,1,2}^{K, \mu}\right)_{i}\right)$. The goodness of fit for the final approximation is $R^{2} \geq 0.99$ for all experiments computed, which is in the usual range in the literature. ${ }^{14}$

For the solution of the household problem, I first transform the model so that the individual state space consists of cash-at-hand instead of stocks and bonds. This reduces the dimension of the state by one. The details on the transformations and the resulting equilibrium definitions can be found in chapter A.2.1. I apply the endogenous grid method of Carroll (2006) when solving the household problem backwards. The wellknown advantage is that Carroll's method avoids expensive root-finding steps in the

\footnotetext{
${ }^{13}$ Using the equity premium instead of the bond return has two advantages: the equity premium fluctuates less, and we can prevent it from becoming negative.

${ }^{14}$ While this is the usual measure reported in the literature, it is not necessarily a good one to evaluate how close the solution is to a true equilibrium. Two complementary measures are the N-step-ahead forecast error Den Haan (2010), and the average and maximum Euler equation errors (see Judd (1992)).
} 
consumption Euler equation. In the case of two assets, it has the additional advantage that instead of solving simultaneously for the optimal amount of two assets, which is a twodimensional root-finding problem, I can keep the total savings amount fixed and solve for the optimal share invested in stock, which is only a one-dimensional problem. See appendix A for details. The Fortran 2003 code and compiled binaries will be published on-line under the GNU General Public license, because its full object-orientation and parallelization contains some originality.

\subsection{Implementation of Borrowing Constraints}

Two types of borrowing constraints are central to this paper, and in general they are not trivial to implement computationally. The baseline economy requires the condition of nonnegative bequests (NNB') to hold. Together with $c>0$, this condition implies a sequence of age- and state-dependent endogenous borrowing constraints, the natural borrowing limits $M_{j}(s, \Phi, z)$. They can be interpreted as the capitalized value of the worst future income stream and have to be calculated explicitly to guarantee that during the simulations there are no negative bequests. The reason that agents might want to take more debt than $M_{j}(s, \Phi, z)$ is that the worst labor income may be very small, and agents expect high income at later ages due to the deterministic life-cycle component $e_{j}$. So if the $M_{j}(s, \Phi, z)$ are not explicitly calculated, then during the simulations it could happen that agents die in debt or have implicit negative consumption. However, the $M_{j}(s, \Phi, z)$ are endogenous objects, since they are a combined restriction on asset positions, asset returns, and labor income. To calculate them, I make the following assumption.

Assumption 1. $\forall(j, \sigma, b, s, \Phi, z)$ :

$$
\left(\sigma_{j}^{\prime}(\sigma, b, s ; \Phi, z)+b_{j}^{\prime}(\sigma, b, s ; \Phi, z)\right) \rightarrow-M_{j}(s, \Phi, z) \Rightarrow \sigma_{j}^{\prime}(\sigma, b, s ; \Phi, z) \rightarrow 0
$$

This does not seem a strong assumption, since all it says is that as the agent approaches his maximum borrowing capacity, he will reduce his investment in the risky asset. This is plausible, because the agent only takes up so much debt to keep consumption positive. Also, if he was borrowing using the risky asset, he would reduce this short position, because in expectation borrowing in stock is much costlier than in bond. I check this assumption both in the household solution as well as in the simulations and never find it 
violated. Under assumption 1, the natural borrowing limits can be calculated recursively as

$$
\begin{aligned}
& M_{J}(s, \Phi, z)=0 \\
& M_{j}(s, \Phi, z)=\frac{1}{1+r_{b}(\Phi)}\left[M_{j+1}(\underline{s}, H(\Phi, z), \underline{z})\right. \\
& \left.\quad-(1-\tau) y_{j+1}(\underline{s}, H(\Phi, z), \underline{z}) I(j+1)-y_{s s}(H(\Phi, z), \underline{z})(1-I(j+1))\right],
\end{aligned}
$$

where $\underline{s}$ is the smallest element of $\mathcal{S}$, which by construction yields the smallest value of the stochastic income component $\eta(s, z)$. Likewise, $\underline{z}$ is the smallest element of $\mathcal{Z}$ and by construction yields the smallest value for $\zeta(z)$. The equation formalizes the notion of the capitalized value of the worst future income stream: for every state today, I calculate the endogenous borrowing limit by subtracting the worst possible income realization tomorrow from the tightest possible borrowing constraint tomorrow and discounting that at the one-period risk-free rate $r_{b}(\Phi) .{ }^{15}$ Assumption 1 essentially ensures that I can use $r_{b}(\Phi)$ for discounting. Of course, in the computation I replace $\Phi$ and $H(\cdot)$ by their approximations given in (16-17). The natural borrowing limits are never binding, because a binding constraint would imply zero consumption at some date-event. Since they never bind, they do not affect the Euler equations in the solution, and during the simulations, I check that the fraction of agents at this lower bound of the distribution $\Phi$ is tiny.

When implementing the zero-borrowing constraint ( $\mathrm{ZB}$ '), one usually faces the numerical difficulty of finding the 'kink point', i. e. the line in the state space where the constraint just binds. This is particularly problematic for high-dimensional state spaces like the present one. However, another advantage of Carroll's method of endogenous gridpoints is that it can deal well with exogenous constraints. We can simply set the lower bound of the grid for total savings $a^{\prime}=\sigma^{\prime}+b^{\prime}$ to zero. More interestingly, note that we can deal with the lower bounds $\left\{M_{j}(s, \Phi, z)\right\}$ in a very similar manner, by setting the lowest gridpoint of $a^{\prime}$ slightly above the corresponding natural borrowing limit (see Hintermaier and Koeniger (2010) for a similar argument).

\footnotetext{
${ }^{15}$ Agents are allowed to borrow against future pension income, if there is any. This does not correspond to the law in the U.S., which prohibits pension income to be pledged for debt. However, since in the model there is perfect enforcement of contracts, there is no reason to distinguish labor income from pension income. Davis, Kubler, and Willen (2006) have a similar specification.
} 
In the following, whenever I talk of an economy without an exogenous borrowing constraint, it means that (ZB') is not imposed, but the nonnegativity of bequests (NNB') is. On the other hand, note that (ZB') implies (NNB').

\subsection{Computational Experiments}

The experiments are designed to expose the effects of idiosyncratic risk and borrowing constraints on the equity premium and to explain the mechanisms behind it. Markets against aggregate risk are incomplete in all economies, so that we have an explicit market price of risk. All economies are recalibrated to have the same capital-output ratio, which implies that the exogenous supply of stocks and bonds remains constant. The details of the (re-)calibrations are described in the next section.

The conceptual sequence of experiments is the following. The baseline economy features complete insurance markets against idiosyncratic risk and no exogenous borrowing constraint. Then I first impose the exogenous zero-borrowing-constraint, and in the tables I call it the ZB economy. This is the thought experiment carried out by Constantinides, Donaldson, and Mehra (2002), so the results can be understood as a quantitative evaluation of their mechanism in a large-scale model. Next, I look at an economy without an exogenous borrowing constraint and without insurance markets against idiosyncratic risk. I will say that idiosyncratic risk is present and call it the IR economy. Note that the nonnegativity of bequests (NNB') has to hold and that the implied endogenous borrowing constraints will differ from the baseline economy. The third economy features both an exogenous zero-borrowing constraint and idiosyncratic risk. So insurance markets against idiosyncratic risk are closed, and I call it the ZB,IR economy.

Then, all the exercises are repeated with a social security system. The corresponding economy names will have an SS attached. As discussed in the introduction, the reason for this specific extension is that social security directly counteracts the forces underlying the mechanism of Constantinides, Donaldson, and Mehra (2002). As can be seen from the equilibrium description, I limit attention to a defined contribution system with a flat pension scheme.

Finally, I will also analyze the effect of a counter-cyclical variance of the idiosyncratic income risk. The experiments will be analogous to the cases where I allow for 
idiosyncratic risk, and I call the economies the CCV economy and the ZB,CCV economy, respectively. Note that in the model description, the possibility CCV was included as the idiosyncratic income shock $\eta(s, z)$ was allowed to also depend on $z$.

\section{Parametrization}

\subsection{Parametrization and Calibration Strategy}

Most of the model parameters are directly set to the values in Gomes and Michaelides (2008) (GM) and Storesletten, Telmer, and Yaron (2007) (STY) to stay comparable to them, since both papers analyze similar asset pricing questions in a large-scale OLG economy with idiosyncratic and aggregate uncertainty. I then calibrate the model to match three statistics in the data that are crucial for asset pricing: the variance of aggregate consumption growth $\operatorname{var}\left(\frac{C_{t+1}}{C_{t}}\right)$, the covariance of aggregate consumption growth with the stock return $\operatorname{cov}\left(\frac{C_{t+1}}{C_{t}}, r_{\sigma, t}\right)$, and the capital-to-output ratio $E\left(\frac{K}{Y}\right) .{ }^{16}$ The variance and covariance of aggregate consumption growth are at the heart of the equity premium puzzle as originally stated by Mehra and Prescott (1985). In section 4.3, I describe how I calibrate the model to match them.

The capital-to-output ratio has a strong impact on the level of returns: when it increases, the stock and the bond return decrease by roughly the same amount. The ratio also determines average aggregate output and the exogenous supply of stocks and bonds, as is clear from eq. (6). Therefore, I keep this ratio constant at the value of 3.3 across all economies. This is achieved by varying the discount factor $\beta$ as shown in table 1 .

Table 1: Values for discount factor $\beta$ for all economies

\begin{tabular}{ccccccccc}
\hline \hline & baseline & ZB & IR & ZB,IR & SS & ZB,SS & CCV & ZB,CCV \\
\hline$\beta$ & 0.97 & 0.96 & 0.91 & 0.90 & 0.99 & 0.99 & 0.90 & 0.90 \\
\hline \hline
\end{tabular}

Notes: The names for the different economies are explained in section 3.3 and as well as in the results section.

${ }^{16}$ STY also match $\operatorname{var}\left(\frac{C_{t+1}}{C_{t}}\right)$ and $E\left(\frac{K}{Y}\right)$, but not $\operatorname{cov}\left(\frac{C_{t+1}}{C_{t}}, r_{\sigma, t}\right)$. 


\subsection{Demographics, Technology, and Preferences}

A model period corresponds to one year. Households enter the model at biological age 22 , retire at the age of 65 , and die at 85 . The deterministic life-cycle productivity profile $\left\{e_{j}\right\}_{1}^{J}$ is estimated from PSID data and displayed in figure 1. The remaining parameters are standard and their value is shown in table 2 together with the source where they are taken from.

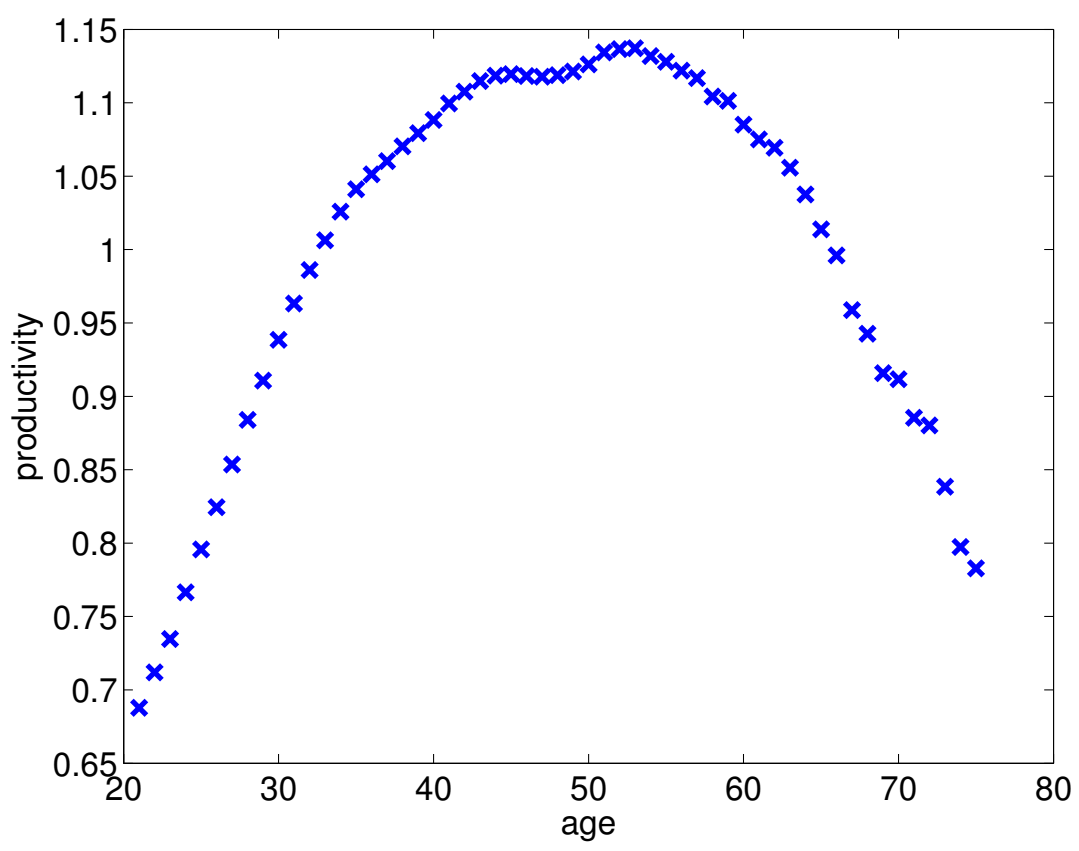

Figure 1: Deterministic life-cycle productivity profile $\left\{e_{j}\right\}_{1}^{J}$ estimated from PSID data.

\subsection{Aggregate Shocks}

There are two types of aggregate shocks: the TFP shock $\zeta(z)$ and the depreciation shock $\delta(z)$. Each can take on two values. I specify a symmetric $2 \times 2$ transition matrix for each, $\pi_{\zeta}$ and $\pi_{\delta}$, and from this construct the $4 \times 4$ transition matrix for the aggregate shocks $\pi_{z} \cdot{ }^{17}$ This allows me to match the autocorrelation of TFP shocks together with the covariance of TFP and depreciation shocks. I jointly calibrate $\pi_{\zeta}, \pi_{\delta}$, and the variance of the depreciation shocks $\sigma_{\delta}$ to match the autocorrelation of TFP shocks, the variance of

\footnotetext{
${ }^{17}$ Details on the construction of the transition matrices can be found in section A.1.2.
} 
Table 2: Values for preference and technology parameters

\begin{tabular}{lcc}
\hline \hline Parameter & Value & Source \\
\hline Discount factor, $\beta$ & cf. table 1 & - \\
Coefficient of relative risk aversion, $\theta$ & 8.0 & STY \\
Elasticity of intertemporal substitution, $\phi$ & 0.5 & GM \\
Capital share, $\alpha$ & 0.36 & STY \\
Debt-equity-ratio, $\bar{d}$ & 0.66 & Croce (2010) \\
Technological growth, $\lambda$ & 0.00 & GM \\
\hline \hline
\end{tabular}

Notes: These parameters are directly set for all economies. If not stated otherwise, the values are taken from Gomes and Michaelides (2008) (GM) and Storesletten, Telmer, and Yaron (2007) (STY).

consumption growth $\operatorname{var}\left(\frac{C_{t+1}}{C_{t}}\right)$, and $\operatorname{cov}\left(\frac{C_{t+1}}{C_{t}}, r_{\sigma, t}\right)$. The target values for $\operatorname{var}\left(\frac{C_{t+1}}{C_{t}}\right)=$ 0.00127 (corresponding to a a standard deviation of 0.036), and $\operatorname{cov}\left(\frac{C_{t+1}}{C_{t}}, r_{\sigma, t}\right)=0.00219$ are those from Mehra and Prescott (1985). ${ }^{18}$ The autocorrelation for TFP $\operatorname{cor}\left(\zeta_{t}, \zeta_{t-1}\right)=$ 0.43 is estimated from NIPA data after linearly detrending the the Solow residual. The values are shown in table 3.

Table 3: Parametrization of aggregate uncertainty

\begin{tabular}{lcc}
\hline \hline Parameter & Value & Target/ Source \\
\hline Mean of TFP shocks, $\bar{\zeta}$ & 1.00 & $\mathrm{GM}$ \\
Std. dev. of TFP shocks, $\sigma_{\zeta}$ & 0.02 & $\mathrm{GM}$ \\
Mean of depreciation shocks, $\bar{\delta}$ & 0.08 & $\mathrm{GM}$ \\
Std. dev. of depreciation shocks, $\sigma_{\delta}$ & 0.07 & $\operatorname{var}\left(\frac{C_{t+1}}{C_{t}}\right)=0.00127$ \\
Transition prob. TFP, $\pi^{\zeta}(1,1)$ & 0.66 & $\operatorname{cor}\left(\zeta_{t}, \zeta_{t-1}\right)=0.43$ \\
Cond. prob. depreciation, $\pi^{\delta}(1 \mid \zeta)$ & 0.50 & $\operatorname{cov}\left(\frac{C_{t+1}}{C_{t}}, r_{\sigma, t}\right)=0.00219$ \\
\hline \hline
\end{tabular}

Notes: The first three parameters are taken from Gomes and Michaelides (2008) (GM); the last three parameters are jointly calibrated to match the three targets.

\footnotetext{
${ }^{18}$ See also the values in Kocherlakota (1996).
} 


\subsection{Idiosyncratic Shocks}

An idiosyncratic shock $s$ affects the household only through the stochastic idiosyncratic component of income $\eta$. Consequently, use estimates of the empirical income process to set the transition matrix for idiosyncratic shocks, $\pi_{s}$. Specifically, I take the estimates from Storesletten, Telmer, and Yaron (2004), because as an extension, I analyze the case of a countercyclical variance of the income risk CCV (see section 5.4). They estimate an income process of the following kind:

$$
\ln (\eta)_{i, t}=\rho \ln (\eta)_{i, t}+\epsilon_{i, t} \quad, \epsilon_{i, t} \sim \mathcal{N}\left(0, \sigma_{\epsilon, t}^{2}\right)
$$

The CCV enters through the time-dependence of the variance of the innovations, $\sigma_{\epsilon, t}^{2}$. However, note that in all experiments but the CCV extension, $\epsilon$ will be homoscedastic. ${ }^{19}$ Their estimates are displayed in table 4. I then use the Rouwenhorst method to create the transition matrix $\pi_{s}$ and the values for $\eta(s, z) .{ }^{20}$ It is important to point how the $\mathrm{CCV}$ maps into the aggregate state of the economy: a high TFP shock is associated with the low CCV and v. v. Thus, the booms in Storesletten, Telmer, and Yaron (2004) are mapped to TFP shocks, not to depreciation shocks. However, I calibrate the correlation between TFP and depreciation shocks explicitly.

Table 4: Parametrization of idiosyncratic uncertainty

\begin{tabular}{lcc}
\hline \hline Parameter & Value & Source \\
\hline Autocorrelation of $\ln (\eta), \rho$ & 0.95 & STY \\
Std. dev. of idios. income shock, $\sigma_{\epsilon}$ & 0.17 & STY \\
Std. dev. of idios. income shock with CCV, $\sigma_{\epsilon}(z)$ & $\{0.21,0.13\}$ & STY \\
Mean of idios. income shock, $\bar{\eta}$ & 1.00 & - \\
\hline \hline
\end{tabular}

Notes: These parameters are directly set for all economies. The values are taken from Storesletten, Telmer, and Yaron (2007) (STY).

\footnotetext{
${ }^{19}$ The homoscedastic variance for $\epsilon$ is calculated as $\sigma_{\epsilon}=\left(\sigma_{\epsilon}(1)+\sigma_{\epsilon}(2)\right) / 2$.

${ }^{20}$ Kopecky and Suen (2010) show that the Rouwenhorst method usually yields a better approximation to the continuous process than traditional methods like Tauchen. More importantly, it fits the CCV case very well, because it will yield different the values for $\eta(s, z)$ for each $z$, but will leave $\pi_{s}$ unchanged.
} 


\section{Results}

\subsection{Asset Prices}

The asset pricing effects of zero-borrowing constraints and of idiosyncratic risk are displayed in table 5. The third column shows the data for the U. S. (1970-1998) as reported by Campbell (2003). There, one can see the well known stylized facts of a low risk-free rate - which here is the bond return $r_{b, t}$ and a high equity premium $E\left(r_{\sigma, t}-r_{b, t}\right)$. The Sharpe ratio, defined as $\frac{E\left(r_{\sigma, t}-r_{b, t}\right)}{\sqrt{\operatorname{Var}\left(r_{\sigma, t}\right)}}$, is a measure of the market price of risk and amounts to 0.31 in the U. S. over this period. Since consumption-based asset pricing models typically can't generate a high equity premium, the Sharpe ratio is helpful in understanding to what extent this is a failure of generating a high price of risk (as opposed to having a too small amount of risk in the economy). Finally, the standard deviation of the bond return much smaller than the standard deviation of the stock return (by a factor of about 10). The table does not report the values for the calibration targets, specifically $\operatorname{var}\left(\frac{C_{t+1}}{C_{t}}\right)=0.00127, \operatorname{cov}\left(\frac{C_{t+1}}{C_{t}}, r_{\sigma, t}\right)=0.00219$, and $E\left(\frac{K}{Y}\right)=3.3$, because all model versions match them very closely. These and other aggregate statistics are relegated to appendix B.

Table 5: Asset pricing moments

\begin{tabular}{lrrrrrr}
\hline \hline Variable & Moment & Data & Baseline & ZB & IR & ZB, IR \\
\hline Bond return, $r_{b, t}$ & Mean & 1.49 & 1.63 & 1.31 & 1.51 & 1.17 \\
& Std. Dev. & 1.69 & 1.13 & 1.13 & 1.05 & 1.03 \\
& AR(1) & 0.57 & 0.92 & 0.91 & 0.90 & 0.90 \\
Stock return, $r_{\sigma, t}$ & Mean & 6.93 & 3.23 & 4.05 & 3.86 & 3.91 \\
& Std. Dev. & 17.5 & 11.7 & 11.7 & 11.7 & 11.7 \\
Equity premium & AR(1) & 0.05 & 0.03 & 0.03 & 0.03 & 0.03 \\
Sharpe ratio & Mean & 5.44 & 1.60 & 2.74 & 2.38 & 2.74 \\
\hline \hline
\end{tabular}

Notes: The empirical moments for the U. S. (1970-1998) are from Campbell (2003). The model equity premium is $E\left(r_{\sigma, t}-r_{b, t}\right)$, and the model Sharpe ratio is $\frac{E\left(r_{\sigma, t}-r_{b, t}\right)}{\sqrt{\operatorname{Var}\left(r_{\sigma, t}\right)}}$.

The model-generated moments of the baseline economy are shown in the second column. The mean and standard deviation of the bond return at 1.63 percent and 1.13 
percent, respectively, are reasonably close to the data. The mean stock return, on the other hand, amounts to less than half the empirical value of 6.93 percent, and the standard deviation of stock returns is about two thirds that of the data. The classic 'equity premium puzzle' is apparent: the model-value of 1.60 percent is far below the empirical 5.44 percent. The Sharpe-ratio of the baseline economy of 0.14 is also far below its empirical counterpart, which implies that even if the standard deviation of stock returns did match the data, the model wouldn't get close to the empirical equity premium.

The picture changes when a zero-borrowing constraint is introduced. The equity premium goes up by more than one percentage point, which represents an increase of 71 percent. This translates into a substantial increase in the Sharpe ratio: at a value of 0.23 , the distance to the empirical value is half that of the baseline economy. Consequently, the mechanisms laid down by Constantinides, Donaldson, and Mehra (2002) in their stylized model survive to this much richer environment. Due to the large number of generations and production with physical capital accumulation, the impact of zeroborrowing constraints on the equity premium is somewhat more moderate than in their quantitative exercise. However, the impact on the Sharpe ratio is similar.

The sixth column shows the numbers for the economy with only idiosyncratic risk (IR), but no exogenous zero-borrowing constraint. Compared to the baseline, the equity premium increases by 0.8 percentage points, which represents an increase of 50 percent, somewhat less than the increase in the $\mathrm{ZB}$ case. The same goes for the Sharpe ratio. This result opposes the many studies with infinitely-lived agents that report basically zero changes in the equity premium (see, e. g. Lucas (1994), and Heaton and Lucas (1996)). Storesletten, Telmer, and Yaron (2008) find very similar numbers for the equity premium, but in their case, the Sharpe ratio actually decreases. ${ }^{21}$ Before analyzing the reasons, let's look at the last column, which shows the economy with both a zero-borrowing-constraint and idiosyncratic risk (ZB,IR). The equity premium and the Sharpe ratio are essentially the same as in the economy with only the zero-borrowing constraint $(\mathrm{ZB})$. This is the most striking finding and a crucial stepping stone to understanding the mechanisms at work. To this aim, I will next show the effect that the exogenous zero-borrowing limit (ZB) and the endogenous natural borrowing limit have on portfolio choices.

\footnotetext{
${ }^{21}$ Note that this is a different paper from the better known Storesletten, Telmer, and Yaron (2007), in which they only look at the asset pricing implications of CCV. I elaborate on the reasons for my different finding in section 5.4.
} 


\subsection{Borrowing Limits and Portfolio Choices}

Recall that in all economies households are subject to the nonnegative bequest constraint. In the baseline and IR case, it leads to state-dependent, endogenous natural borrowing limits, which are computed according to (18). Figure 2 shows these natural borrowing limits for the baseline and the IR case, together with the zero-borrowing limit and a natural borrowing limit for an infinitely-lived agent. Note that the limits are defined on total savings, i. e. $b_{j}^{\prime}+\sigma_{j}^{\prime} \geq M_{j}$, and that the graph shows the average over all states, i. e. the mean of state-dependent limits. The dotted line for the infinitely-lived agent is calculated like in Aiyagari (1994), using the idiosyncratic income shocks, the average wage, and the average bond return from the IR economy. ${ }^{22}$ The three lines for the baseline, the IR, and the ZB case meet at zero when the agent retires, since he does not have retirement income. Before retirement, the natural borrowing limit in the IR economy is much tighter, because the worst possible income realization is much closer to zero, due to the presence of idiosyncratic shocks. Indeed it is closer to the $\mathrm{ZB}$ line, which could help explain why the equity premium in the IR case increases not quite as much as in the ZB case. The (ZB,IR) case is not shown in the figure, because its line corresponds to the $\mathrm{ZB}$ line. As was just discussed, the equity premium and the Sharpe ratio are also the same for ZB and (ZB,IR). Finally, the line for the infinitely-lived agent looks like a lower bound. It is, but only to the IR line, not necessarily to the ZB line. The reason that $\mathrm{ZB}$ lies above the line for the infinitely-lived agent is the numerical calibration. This sheds light on why idiosyncratic risk in infinitely-lived economies does not have an impact on the equity premium: even with idiosyncratic risk, the Aiyagari-style natural borrowing limit is very lax (see, e.g. Zhang (1997)).

The essence of figure 2 and the preceding paragraph is that it seems as if the endogenous, natural borrowing limit is responsible for the high equity premium and Sharpe ratio in the IR case. This is supported by the fact that the ZB case and the (ZB,IR) case have the same borrowing limit and the same equity premium and Sharpe ratio. To understand how the borrowing constraints affect the household, I now turn to portfolio choices.

Figure 3 shows the average total savings, $b_{j}^{\prime}+\sigma_{j}^{\prime}$, and the average share invested in stock, $\frac{\sigma_{j}^{\prime}}{b_{j}^{\prime}+\sigma_{j}^{\prime}}$, over the life-cycle. ${ }^{23}$ Negative total savings mean that the agent is

\footnotetext{
${ }^{22}$ It is correct to take the average, aggregate wage and bond return, instead of the worst realizations, because in the graph we average over all states.

${ }^{23}$ Averages are taken over the distribution $\Phi$.
} 


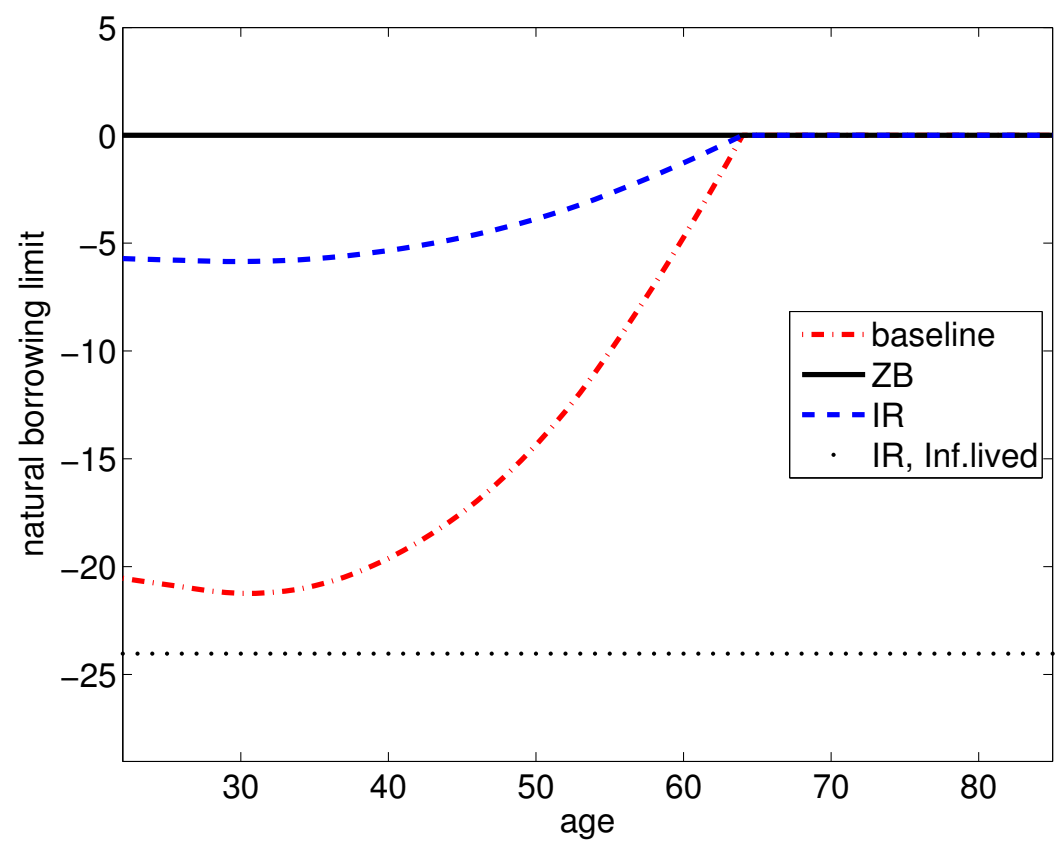

Figure 2: Natural borrowing limits $M_{j}$ for the baseline economy, the economy with a zero-borrowing-constraint (ZB), the economy with idiosyncratic risk (IR), and an economy with infinitely-lived agents and idiosyncratic risk (IR, Inf.lived). 
borrowing to increase consumption. But he can also borrow to invest in stock, which is the case whenever the share invested in stock is larger than one. Generally speaking, both total savings and the share invested in stock correspond to the typical life-cycle profile. Households accumulate savings until retirement, then they dissave and reach zero in the final period. The young invest heavily in stock, because their life-time expected income is relatively safe and they want to benefit from the large returns on equity. As their capitalized value of labor income diminishes over age, they reduce their share in stock.

First, I want to highlight that in the baseline economy, the households do have negative total savings, i. e. net debt positions. Recall that only the average is plotted, so individual households might be taking up much more debt. They can do so because the natural borrowing limit in this economy is very lax. They want to do so in order to smooth consumption, both in response to aggregate income fluctuations, and in view of the larger future income due to the steeply increasing deterministic productivity profile.

Turning to the economy with a zero-borrowing constraint, we see in figure 3 that the young now are stuck at zero total savings. They would like to borrow by short-selling the bond and invest in stock, but are not allowed to. Consequently, the share invested in stock is flat at one until the age of 50, and only then starts decreasing. After the age of 45, households in the ZB economy hold a substantially larger fraction of their assets in stock than in the baseline economy. The reason is the following: since the young can't hold as much stock as in the baseline, but the stock supply remains constant, the equity premium has to rise to induce the middle aged and old to hold the stock. In fact, it has to rise substantially, because the middle-aged and old households do not like stock as an asset to save for retirement. Since they have no social security income, their consumption growth will covary strongly with returns, thus the large equity premium. This is the essence of Constantinides, Donaldson, and Mehra (2002).

Now we come to the most interesting part of figure 3 , the economy with idiosyncratic risk (and no zero-borrowing constraint). The total savings graph shows only very few negative total savings. This is in line with the much tighter natural borrowing limit displayed in figure 2. At the same time, the young invest less in stock and the old more than in the baseline case. In other words, the share invested in stock in the IR case is right in between the baseline and the $\mathrm{ZB}$ case. This highlights the similarity of introducing a zero-borrowing constraint to introducing idiosyncratic risk. The tight 

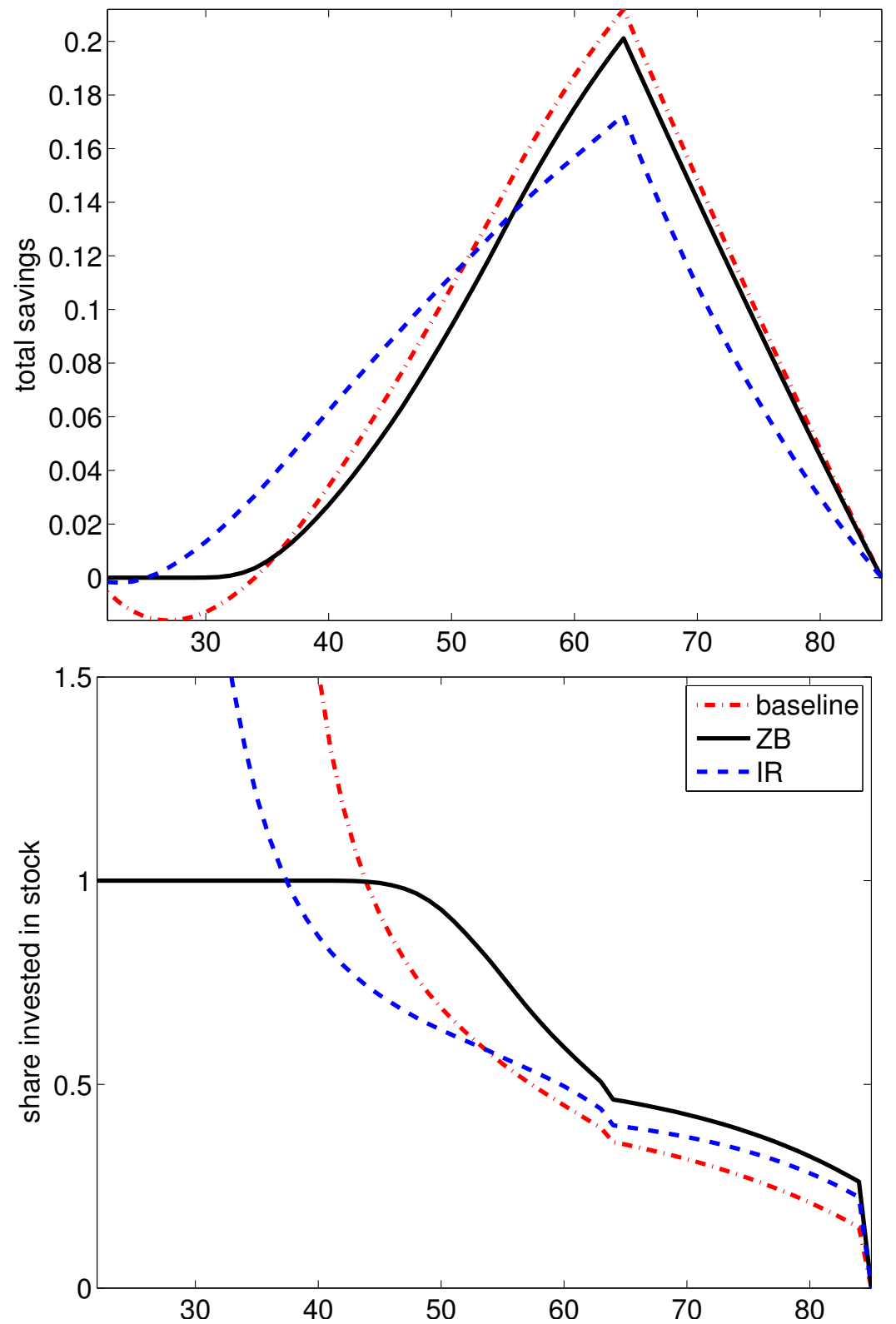

Figure 3: Life-cycle profiles for total savings, $b_{j}^{\prime}+\sigma_{j}^{\prime}$, and the share invested in stock, $\frac{\sigma_{j}^{\prime}}{b_{j}^{\prime}+\sigma_{j}^{\prime}}$; baseline economy, economy with zero-borrowing constraint (ZB), and economy with idiosyncratic risk (IR). 
endogenous borrowing limits not only prevent the young households from borrowing, but also shift the life-cycle of portfolios in a fashion similar to that of the zero-borrowing constraint. The young hold less stock to avoid being pushed to the endogenous borrowing limit by bad returns. This means that they accumulate assets less quickly, so that the older households have to hold a larger share of equity to realize enough consumption in retirement. However, this means that the covariance of consumption growth of the households facing or being in retirement with stock returns increases. This increases the equity premium. Obviously, the channel is basically the same as with the zero-borrowingconstraint.

Figure 4 displays the average life-cycle profiles for the economy with both a zeroborrowing constraint and idiosyncratic risk. The lines for the ZB economy are plotted as a reference, because the two economies yield the same equity premium and Sharpe ratio. When households face both idiosyncratic risk and a zero-borrowing constraint, they start to accumulate positive savings immediately. The reason is that they want to avoid a binding borrowing constraint, because then a sequence of bad idiosyncratic shocks will directly translate into diminishing consumption. As a consequence, the $(\mathrm{ZB}, \mathrm{IR})$ line runs above the (ZB) line until the age of 55. On first glance, it might seem surprising that the life-cycle profiles of the share invested in stock differ so much, given that the two economies yield the same results for the equity premium and the Sharpe ratio. Specifically, households reduce their share invested in stock quickly when they also have idiosyncratic risk, which can be explained again by their desire to avoid the borrowing constraint. Thus the prefer the safer bond. However, from the age of 60 onward, the two curves differ only very slightly, which is not surprising, since there is no more idiosyncratic labor income risk after retirement at $65 .^{24}$ The drop in the relative demand for stock of the households aged 30 to 60 puts an upward pressure on the equity premium, even if the drop is smaller than those observed in 3 . The fact that the premium doesn't move means that it is still the households aged 60 and over who price the stock. Therefore, the mechanisms laid down by Constantinides, Donaldson, and Mehra (2002) are robust to the introduction of idiosyncratic risk.

\footnotetext{
${ }^{24}$ In the graph for the share invested in stock, one line seems to lie below the other everywhere. At the same time the total savings curve shifts, so that the aggregate demand for both assets doesn't change and is equal to the constant aggregate supply for each.
} 

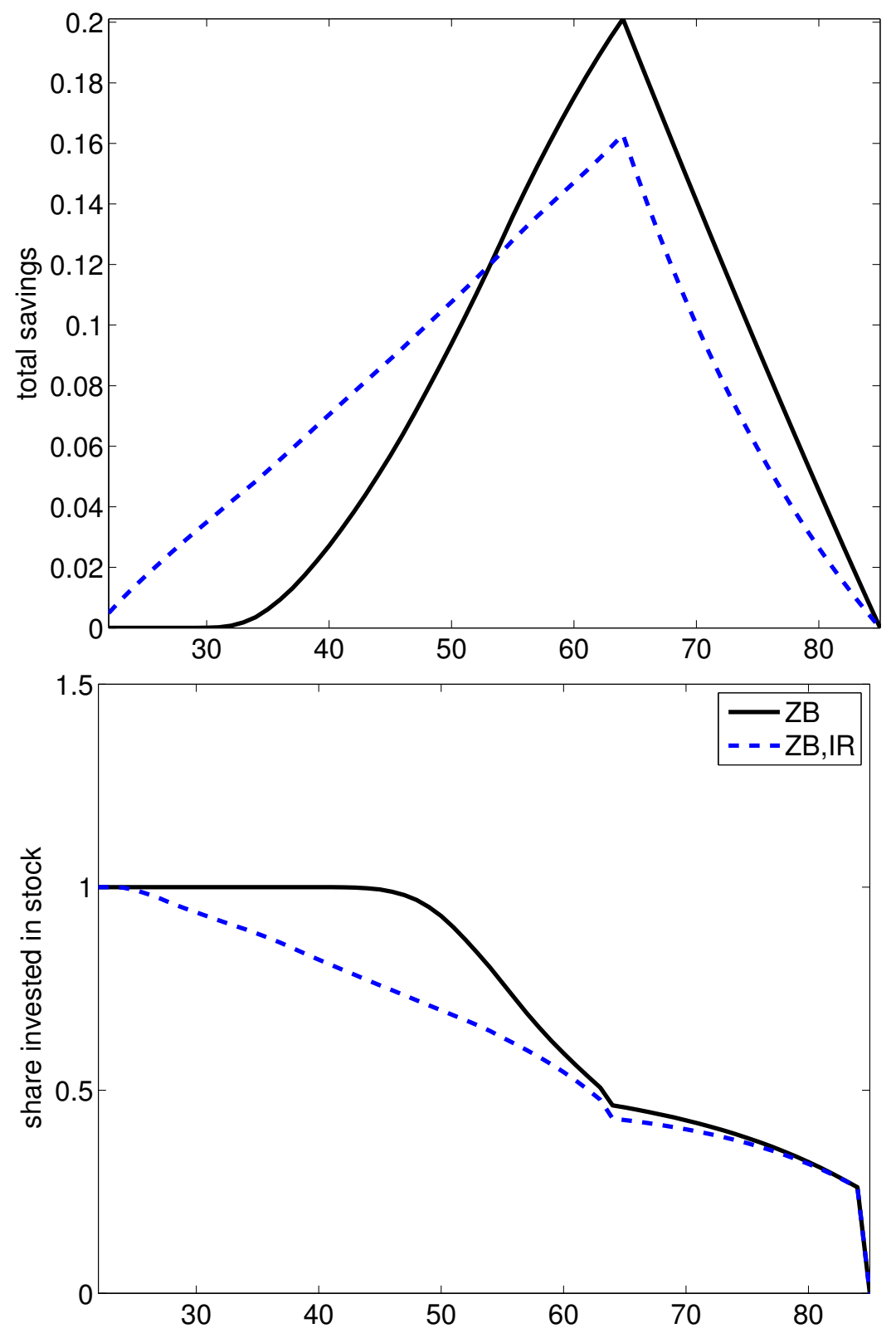

Figure 4: Life-cycle profiles for total savings, $b_{j}^{\prime}+\sigma_{j}^{\prime}$, and the share invested in stock, $\frac{\sigma_{j}^{\prime}}{b_{j}^{\prime}+\sigma_{j}^{\prime}}$; zero-borrowing economy (ZB) and zero-borrowing economy with idiosyncratic risk ( $\mathrm{ZB}, \mathrm{IR})$. 


\subsection{Social Security}

The previous section has shown that the mechanism of Constantinides, Donaldson, and Mehra (2002), namely that the households facing retirement price the stock, survives to richer environments with production, long life-spans, and idiosyncratic risk. Their argument seems to crucially depend on the absence of social security, because only then does the consumption growth of the retired covary strongly with stock returns. If, on the other hand, the retired receive social security benefits, then they have a potentially very efficient way of smoothing their consumption, because the shocks to stock returns display a very low persistence in both the data and the model, as was shown in table 5.

The results in table 6 confirm this intuition. The value for the social security contribution rate $\tau$ is set to the current value in the U. S. of 12 percent. Social security strongly decreases the equity premium if a zero-borrowing constraint is present, but it has basically no effect on the premium in the baseline economy. In the baseline economy,

Table 6: Asset pricing moments with social security

\begin{tabular}{lllccr}
\hline \hline Variable & Moment & Baseline & SS & ZB & ZB,SS \\
\hline Bond return, $r_{b, t}$ & Mean & 1.63 & 1.93 & 1.31 & 1.56 \\
Equity premium & Mean & 1.60 & 1.58 & 2.74 & 2.07 \\
Sharpe ratio & Mean & 0.14 & 0.14 & 0.23 & 0.17 \\
\hline \hline
\end{tabular}

Notes: The numbers in columns 3 and 5 are the same as in table 5. Columns 4 and 6 show the baseline economy with social security (SS) and with a zero-borrowing constraint and social security (ZB,SS). The social security contribution rate is set to the U. S. value of 12 percent. See table 5 for further explanations.

there are two opposing forces: the older households don't require such a high equity premium, because their retirement consumption covaries less with stock returns if they receive social security income. This decreases the equity premium. On the other side, the young invest a smaller share in stock, because they do not need to accumulate as much savings for retirement. This increases the equity premium. The net effect in the present calibration is zero. However, with zero borrowing constraints, only the first channel is at work, while the second is basically shut down. As can be seen in figure 5, the reduction of the share invested in stock is small, because both in (ZB) and (ZB,SS) the upper bound is binding. Figure 5 shows that households save less for retirement in the SS economy. However, they start saving much earlier because of the higher average returns, whereby 

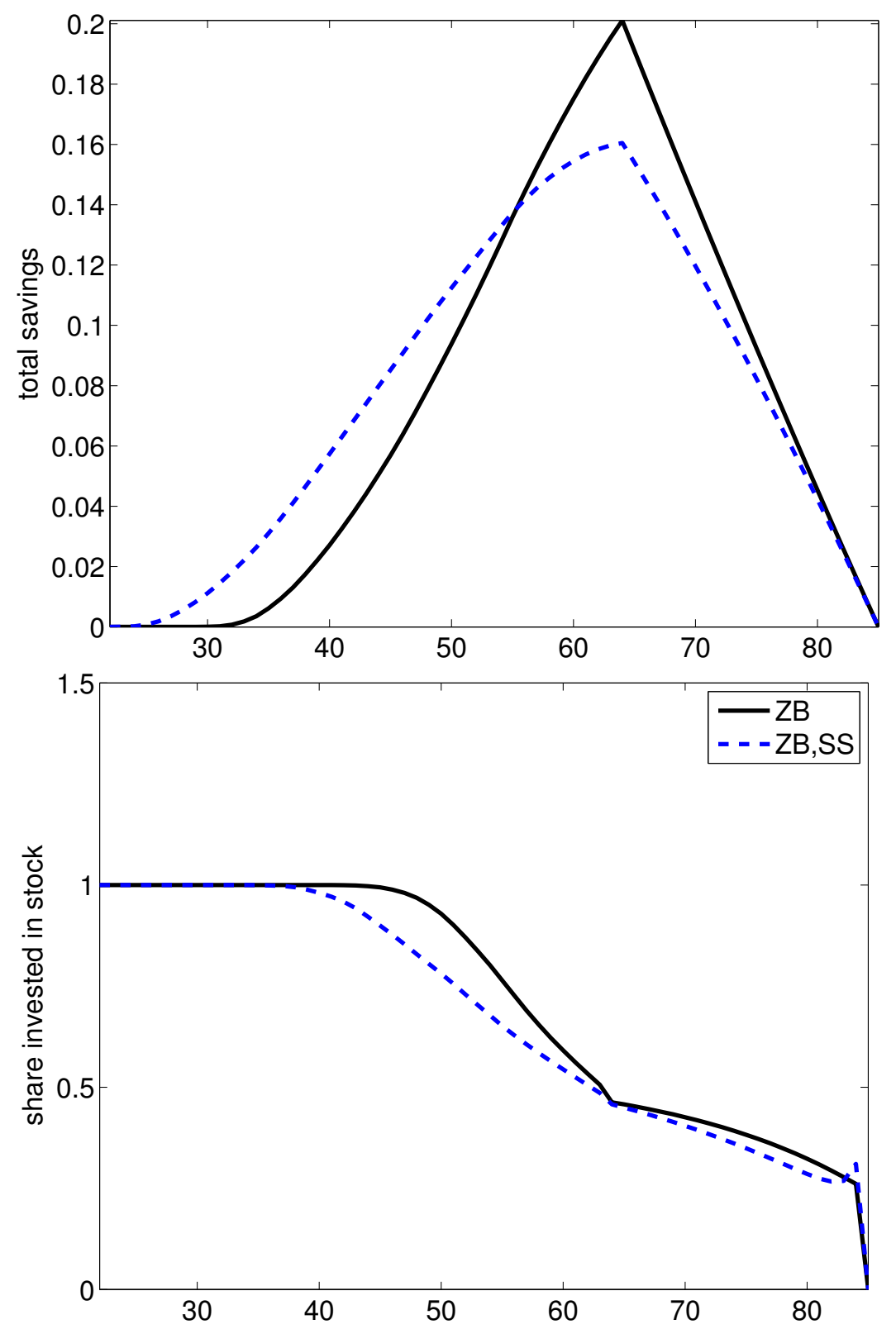

Figure 5: Life-cycle profiles for total savings, $b_{j}^{\prime}+\sigma_{j}^{\prime}$, and the share invested in stock, $\frac{\sigma_{j}^{\prime}}{b_{j}^{\prime}+\sigma_{j}^{\prime}}$; zero-borrowing economy (ZB) and zero-borrowing economy with social security (ZB,SS). 
they achieve a much flatter lifetime consumption profile. It is worth pointing out that figures 4 and 5 look qualitatively very similar, but lead to opposing effects on the equity premium. The reason for the different results is of course the differing effects on the consumption growth of the retired: idiosyncratic risk does not affect its covariance with stock returns, whereas social security does.

In order to evaluate whether the tight natural borrowing limits in an economy with idiosyncratic risk again play a similar role to the zero-borrowing constraints, I repeat the same comparison for the IR economy and the (IR,SS) economy. I find results similar, but less strong than the once just reported. The equity premium decreases by 0.4 percentage points (as opposed to 0.67 in table 6), and the life-cycle profiles shift in a similar way as in figure 5. This again lends support to the hypothesis that the natural borrowing limits play an important role.

\subsection{Countercyclical Variance of Income Risk}

As an extension, I analyze how the results change when the idiosyncratic income risk has a countercyclical variance (CCV). This is very similar to Storesletten, Telmer, and Yaron (2007) and Storesletten, Telmer, and Yaron (2008), but they do not look at zero-borrowing constraints. Table 7 compares the economy with homoscedastic idiosyncratic risk (IR) to the one with a countercyclical variance (CCV), and then compares these two cases with borrowing constraints present, i. e. (ZB,IR) to (ZB,CCV). I find that the equity premium and the Sharpe ratio don't change much in the first comparison, and even less in the second. The result that CCV does not have a strong impact in this model is also reflected in the portfolio choices of the household in figure 6 , which barely change.

Table 7: Asset pricing moments with CCV

\begin{tabular}{lllccr}
\hline \hline Variable & Moment & IR & CCV & ZB,IR & ZB,CCV \\
\hline Bond return, $r_{b, t}$ & Mean & 1.51 & 1.74 & 1.17 & 1.06 \\
Equity premium & Mean & 2.38 & 2.49 & 2.74 & 2.78 \\
Sharpe ratio & Mean & 0.20 & 0.21 & 0.23 & 0.23 \\
\hline \hline
\end{tabular}

Notes: The numbers in columns 3 and 5 are the same as in columns 6 and 7 of table 5; economy with countercyclical variance of idiosyncratic income risk (CCV), and economy with a zero-borrowing constraint and CCV (ZB,CCV). See table 5 for further explanations. 

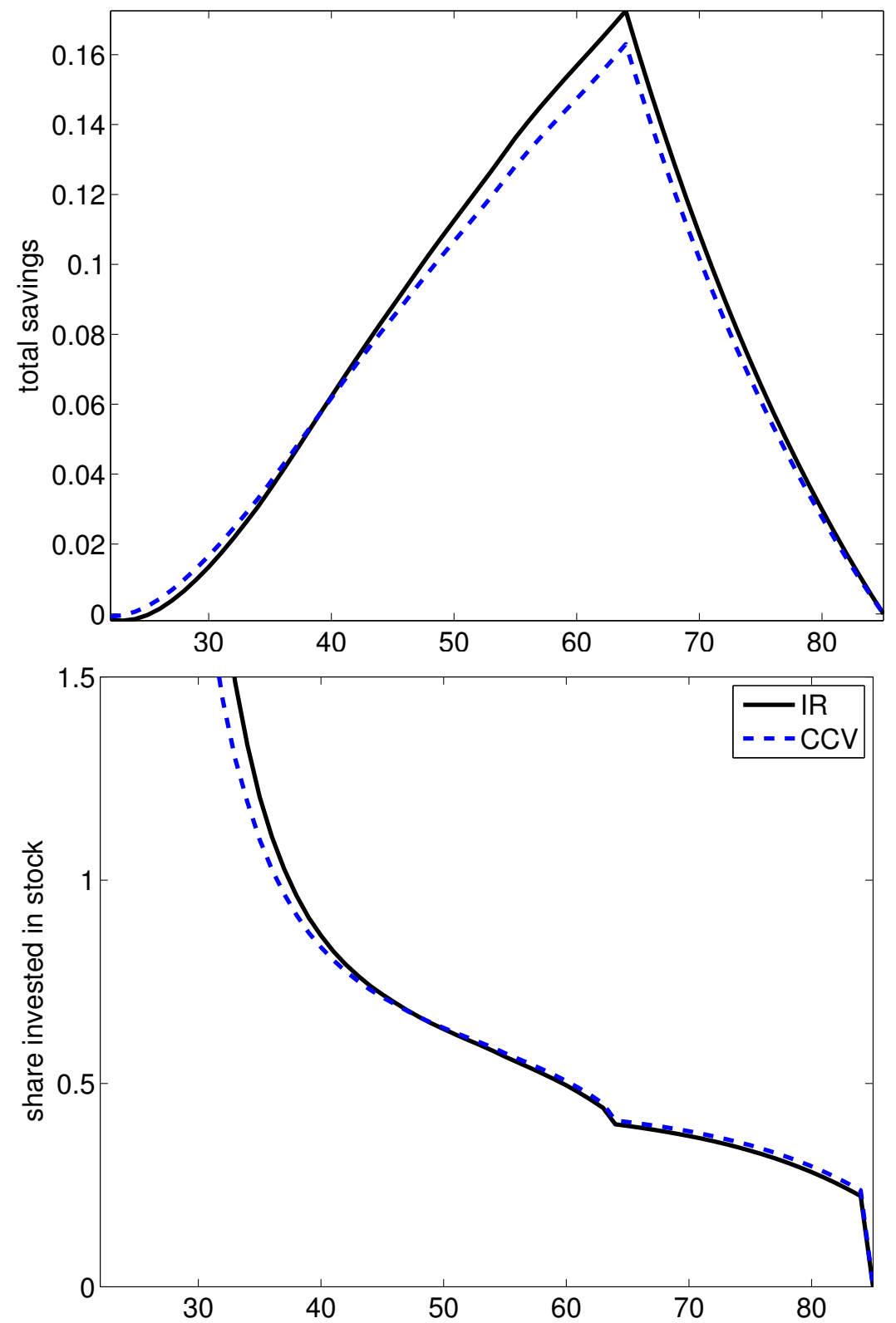

Figure 6: Life-cycle profiles for total savings, $b_{j}^{\prime}+\sigma_{j}^{\prime}$, and the share invested in stock, $\frac{\sigma_{j}^{\prime}}{b_{j}^{\prime}+\sigma_{j}^{\prime}}$; economy with idiosyncratic risk (IR) and economy with idiosyncratic risk and a countercyclical variance of the idiosyncratic income shocks (CCV).

The reason I find a smaller effect of CCV than Storesletten, Telmer, and Yaron (2008) lies in a slightly different calibration. ${ }^{25}$ They have two aggregate states: the economic

\footnotetext{
${ }^{25}$ Note that table 3 in Storesletten, Telmer, and Yaron (2008) shows results that are similar to the ones
} 
expansion features a 'good' TFP shock together with a small depreciation shock, and v. v. for the recession. The variance of idiosyncratic income shocks is larger in a recession. In contrast, I calibrate the co-movements of TFP and depreciation shocks to match the covariance of consumption growth with stock returns in the data. Like in STY, the variance of the income risk is high when the TFP shock is 'bad', but this does not necessarily imply a large depreciation shock in my case. It is then clear that the effect of CCV must be stronger in STY, because households can receive a larger, adverse idiosyncratic income shock if and only if the aggregate wage and stock returns are low. To sum up this section, the main new finding regarding CCV is that it does not increase the equity premium if there is an exogenous zero borrowing constraint. This should not be too surprising given the previous results on homoscedastic, idiosyncratic risk.

\section{Conclusion}

This paper has shown that in an overlapping generations economy, idiosyncratic risk has a similar effect to an exogenous borrowing constraint, because it tightens the natural borrowing limit. As a consequence, idiosyncratic risk increases the equity premium by a similar amount like an exogenously imposed zero-borrowing-limit. This seems to oppose several irrelevance results, like Constantinides and Duffie (1996) or Krueger and Lustig (2010), which state that a countercyclical variance is necessary for idiosyncratic risk to have asset pricing effects. However, the present setup differs in several respects. Probably the most important difference the life-cycle, which gives rise to asset trading that results in a subgroup of the population holding most of the stock. Another interesting finding was that when idiosyncratic risk is added in an economy with a zero-borrowing constraint, then the equity premium does not increase. This is so because the zeroborrowing constraint is tighter than the natural borrowing limit, so that the latter is ineffective, and only the first affects the pricing of the assets.

I also looked at the case with an idiosyncratic variance of the income risk. In contrast to most of the quantitative literature, I find that it does not add much on top of the case

presented here for a risk aversion coefficient of 3. Specifically, in that case, they find that idiosyncratic risk without $\mathrm{CCV}$ accounts for most of the increase in the equity premium and the Sharpe ratio. Their results are qualitatively different for a risk aversion of 8 , but in that case adding idiosyncratic risk actually decreases the equity premium and the Sharpe ratio. So overall their evidence is inconclusive. The better known paper Storesletten, Telmer, and Yaron (2007) does not report the case with homoscedastic variance. 
of a homoscedastic variance. The reason is that I calibrate the depreciation and TFP shocks to match the covariance of aggregate consumption growth with stock returns. However, this implies that aggregate wages and returns are not perfectly negatively correlated like in Storesletten, Telmer, and Yaron (2007), but instead are closer to the empirical correlation. As a consequence, it can happen that in a recession, i. e. when an adverse TFP shock hits the economy, the stock return goes up. Then, agents do not mind the countercyclical variance as much, because they are somewhat hedged by the less-than-perfect correlation of wages with stock returns. In future work, it would be interesting to analyze the sensitivity of the countercyclical variance of income risk quantitatively in a structured way.

Finally, I have shown that the equity-premium effect of the borrowing constraint largely disappears when the retired receive social security income. However, I looked only at one specific system, namely a Pay-As-You-Go system with a constant contribution rate and full redistribution. While a constant benefits system should yield similar results, a system that does not fully redistribute and instead ties benefits to contributions might yield different results. If, for example, benefits are tied only to very few income realizations, then the system might even increase the equity premium. This is left for future research.

\section{References}

ÁBrahÁM, Á. AND E. CARCELES-PovedA (2010): "Endogenous trading constraints with incomplete asset markets," Journal of Economic Theory, 145, 974-1004.

AiYAgARI, S. R. (1994): “Uninsured Idiosyncratic Risk and Aggregate Saving," The Quarterly Journal of Economics, 109, 659-684.

Alvarez, F. And U. J. Jermann (2000): "Efficiency, Equilibrium, and Asset Pricing with Risk of Default," Econometrica, 68, 775-797.

- (2001): "Quantitative Asset Pricing Implications of Endogenous Solvency Constraints," The Review of Financial Studies, 14, 1117-1151.

Auerbach, A. J. And L. J. Kotlikoff (1987): Dynamic Fiscal Policy, Cambridge, MA: Cambridge University Press. 
Boldrin, M., L. J. Christiano, And J. D. M. Fisher (1995): “Asset Pricing Lessons for Modeling Business Cycles,” NBER Working Paper Series, No. 5262, $1-52$.

CAmpbell, J. Y. (2003): “Consumption-Based Asset Pricing," in Handbook of the Economics of Finance, ed. by G. M. Constantinides, M. Harris, and R. Stulz, Elsevier, 803-887.

CAO, D. (2012): "Collateral Shortages, Asset Price and Investment Volatility with Heterogeneous Beliefs," .

CArroll, C. D. (2006): “The Method of Endogenous Gridpoints for Solving Dynamic Stochastic Optimization Problems," Economics Letters, 91, 312-320.

Constantinides, G. M., J. B. Donaldson, And R. Mehra (2002): "Junior Can't Borrow: A New Perspective on the Equity Premium Puzzle," The Quarterly Journal of Economics, 117, 269-296.

Constantinides, G. M. And D. Duffie (1996): "Asset Pricing with Heterogeneous Consumers," Journal of Political Economy, 104, 219-240.

Croce, M. M. (2010): "Long-Run Productivity Risk: A New Hope for ProductionBased Asset Pricing?" SSRN Electronic Journal.

Davis, S. J., F. Kubler, And P. Willen (2006): "Borrowing Costs and the Demand for Equity over the Life Cycle," The Review of Economics and Statistics, $88,348-362$.

Deaton, A. (1991): “Saving and Liquidity Constraints," Econometrica, 59, 12211248.

DEN HAAN, W. (2010): "Assessing the accuracy of the aggregate law of motion in models with heterogeneous agents," Journal of Economic Dynamics and Control, 34, 79-99.

EPSTEIn, L. G. AND S. E. ZIN (1989): "Substitution, Risk Aversion, and the Temporal Behavior of Consumption and Asset Returns: A Theoretical Framework," Econometrica, 57, 937-969.

Gomes, F. J. And A. Michaelides (2008): “Asset Pricing with Limited Risk Sharing and Heterogeneous Agents," The Review of Financial Studies, 21, 
$415-448$.

Heaton, J. AND D. J. LuCAS (1996): "Evaluating the Effects of Incomplete Markets on Risk Sharing and Asset Pricing," Journal of Political Economy, 104, 443-487.

Hintermaier, T. And W. Koeniger (2010): “The method of endogenous gridpoints with occasionally binding constraints among endogenous variables," Journal of Economic Dynamics and Control, 34, 2074-2088.

JuDD, K. L. (1992): "Projection Methods for Solving Aggregate Growth Models," Journal of Economic Theory, 58, 410-452.

Kocherlakota, N. R. (1996): “The Equity Premium: It's Still a Puzzle,” Journal of Economic Literature, 34, 42-71.

Kopecky, K. A. AND R. M. Suen (2010): "Finite State Markov-Chain Approximations to Highly Persistent Processes," Review of Economic Dynamics, 13, $701-714$.

KREBS, T. AND B. WiLSON (2004): "Asset returns in an endogenous growth model with incomplete markets," Journal of Economic Dynamics and Control, $28,817-839$.

Kreps, D. M. AND E. L. Porteus (1978): “Temporal Resolution of Uncertainty and Dynamic Choice Theory," Econometrica, 46, 185-200.

Krueger, D. AND F. Kubler (2004): "Computing Equilibrium in OLG Models with Stochastic Production," Journal of Economic Dynamics and Control, 28, 1411-1436.

KRUEGER, D. AND H. LUSTIG (2010): "When is market incompleteness irrelevant for the price of aggregate risk (and when is it not)?" Journal of Economic Theory, 145, 1-41.

Krusell, P., T. Mukoyama, And J. A. A. Smith (2011): “Asset prices in a Huggett economy," Journal of Economic Theory, 146, 812-844.

Krusell, P. AND J. A. A. Smith (1997): “Income and Wealth Heterogeneity, Portfolio Choice, and Equilibrium Asset Returns," Macroeconomic Dynamics, $1,387-422$. 
(1998): "Income and Wealth Heterogeneity in the Macroeconomy," Journal of Political Economy, 106, 867-896.

Kubler, F. And H. Polemarchakis (2004): "Stationary Markov equilibria for overlapping generations," Economic Theory, 24, 623-643.

LEVINE, D. K. AND W. R. ZAme (1996): "Debt constraints and equilibrium in infinite horizon economies with incomplete markets," Journal of Mathematical Economics, 26, 103-131.

_ (2002): “Does Market Incompleteness Matter?” Econometrica, 70, 18051839.

LUCAS, D. J. (1994): “Asset pricing with undiversifiable income risk and short sales constraints: Deepening the equity premium puzzle," Journal of Monetary Economics, 34, 325-341.

Ludwig, A. (2007): "The Gauss-Seidel-quasi-Newton method: A hybrid algorithm for solving dynamic economic models," Journal of Economic Dynamics and Control, 31, 1610-1632.

Magill, M. AND M. QUINZII (1994): “Infinite Horizon Incomplete Markets,” Econometrica, 62, 853-880.

Menra, R. And E. C. Prescott (1985): “The Equity Premium: A Puzzle," Journal of Monetary Economics, 15, 145-161.

MiAO, J. (2006): "Competitive equilibria of economies with a continuum of consumers and aggregate shocks," Journal of Economic Theory, 128, 274-298.

Ríos-RULL, J.-V. (1994): "On the quantitative importance of market completeness," Journal of Monetary Economics, 34, 463-496.

Ríos-Rull, J.-V. (1996): "Life-Cycle Economies and Aggregate Fluctuations," Review of Economic Studies, 63, 465-489.

Storesletten, K., C. I. Telmer, And A. Yaron (2004): “Cyclical Dynamics in Idiosyncratic Labor Market Risk,” Journal of Political Economy, 112, 695717.

(2007): “Asset Pricing with Idiosyncratic Risk and Overlapping Generations," Review of Economic Dynamics, 10, 519-548. 
(2008): "Chapter 14 - Asset Prices and Intergenerational Risk Sharing: The Role of Idiosyncratic Earnings Shocks," in Handbook of the Equity Risk Premium, ed. by R. Mehra, San Diego: Elsevier, 565-590.

Telmer, C. I. (1993): “Asset-Pricing Puzzles and Incomplete Markets,” The Journal of Finance, 48, 1803-1832.

ZHANG, H. H. (1997): "Endogenous Borrowing Constraints with Incomplete Markets," The Journal of Finance, 52, 2187-2209.

\section{Appendix}

\section{A Computational Solution}

\section{A.1 Aggregate Problem}

\section{A.1.1 Mean Shock Equilibrium}

As an initialization step, I solve for a degenerate path of the economy where the realizations of all aggregate shocks are at their respective means. I accordingly set $z=\bar{z}=\mathbb{E} z$ and $\delta=\bar{\delta}=\mathbb{E} \delta$. I assume that households accurately solve their forecasting problem for each realization of the aggregate state. This means that I approximate the above approximate law of motion as

$$
\left(k^{\prime}, \mu^{\prime}\right)=\hat{\hat{H}}\left(k, \mu, \bar{z}, \bar{z}^{\prime}\right)
$$

Observe that in the two stationary equilibria of the model, I have that fixed point relation

$$
\left(k^{\prime}, \mu^{\prime}\right)=\hat{\hat{H}}\left(k, \mu, \bar{z}, \bar{z}^{\prime}\right)=(k, \mu)
$$

With these assumptions, I can solve the mean shock path by standard Gauss-Seidel iterations as, e.g., described in Auerbach and Kotlikoff (1987). I adopt the modifications described in Ludwig (2007). While the numerical methods are the same as in the solution to a deterministic economy, the actual behavior of households fully takes into account the stochastic nature of the model. This also means that I solve the household problem 
using recursive methods and store the solutions to the household problem on grids of the idiosyncratic state $x$. The fixed-point computed in this auxiliary equilibrium gives $k^{m s}$ and $\mu^{m s}$ as aggregate moments and cross-sectional distributions of agents as induced by the mean shock path. I denote these distributions by $\Phi^{m s}$.

\section{A.1.2 Recursive Equilibrium}

In order to solve for the stochastic recursive equilibria of the model, I use simulation methods. To this end, I specify the approximate law of motion as:

$$
\begin{aligned}
& \ln \left(k_{t+1}\right)=\psi_{0}^{k}(z)+\psi_{1}^{k}(z) \ln \left(k_{t}\right)+\psi_{2}^{k}(z) \ln \left(k_{t+1}\right) \\
& \ln \left(\mu_{t+1}\right)=\psi_{0}^{\mu}\left(z^{\prime}\right)+\psi_{1}^{\mu}\left(z^{\prime}\right) \ln \left(k_{t+1}\right)+\psi_{2}^{\mu}\left(z^{\prime}\right) \ln \left(k_{t+1}\right)
\end{aligned}
$$

Like in Krusell and Smith (1997), the forecast for $k_{t+1}$ is used to forecast $\mu_{t+1}$. Intuitively, $k_{t+1}$ contains a lot of information on the savings choice of the agent and therefore on the returns next period. Note that, in each period, $\mu_{t}$ is an "endogenous state", the realization of which has to be pinned down in that particular period (in contrast to $k_{t}$ which is given in period $t$ from decisions $t-1$ ). As in the standard application of the Krusell and Smith (1998) method, the coefficients also depend on the realization of the aggregate state, $z$.

To construct the grids for the the aggregate states $k$ and $\mu, \mathcal{G}^{k}, \mathcal{G}^{\mu}$, define scaling factors $s^{k}$ and $s^{\mu}$ and the number of grid points, $n$. I set $s^{k}=0.8 s^{\mu}=0.6$, and $n=7$. Using these factors, I construct symmetric grids around $k^{m s}, \mu^{m s}$.

I assume that aggregate risk is driven by a four state Markov chain with support $Z=\left\{z_{1}, \ldots, z_{4}\right\}$ and transition matrix $\pi=\left(\pi_{i j}\right)$. Each aggregate state maps into a combination of low or high technology shocks and low or high physical capital depreciation. To be concrete, I let

$$
\zeta(z)=\left\{\begin{array}{l}
1-\bar{\zeta} \text { for } z \in z_{1}, z_{2} \\
1+\bar{\zeta} \text { for } z \in z_{3}, z_{4}
\end{array} \quad \text { and } \delta(z)=\left\{\begin{array}{l}
\delta_{0}+\bar{\delta} \text { for } z \in z_{1}, z_{3} \\
\delta_{0}-\bar{\delta} \text { for } z \in z_{2}, z_{4}
\end{array}\right.\right.
$$

With this setup, $z_{1}$ corresponds to a low wage and a low return, while $z_{4}$ corresponds to a high wage and a high return.

To calibrate the entries of the transition matrix, denote by $\pi^{\zeta}=\pi\left(\zeta^{\prime}=1-\bar{\zeta} \mid \zeta=\right.$ $1-\bar{\zeta})$ the transition probability of remaining in the low technology state. Assuming that 
the transition of technology shocks is symmetric, I then also that $\pi\left(\zeta^{\prime}=1+\bar{\zeta} \mid \zeta=1+\right.$ $\bar{\zeta})=\pi^{\zeta}$ and, accordingly $1-\pi^{\zeta}=\pi\left(\zeta^{\prime}=1-\bar{\zeta} \mid \zeta=1+\bar{\zeta}\right)=\pi\left(\zeta^{\prime}=1+\bar{\zeta} \mid \zeta=1-\bar{\zeta}\right)$.

To govern the correlation between technology and depreciation shocks, let the probability of being in the high (low) depreciation state conditional on being in the low (high) technology state, assuming symmetry, be $\pi^{\delta}=\pi\left(\delta^{\prime}=\delta_{0}+\bar{\delta} \mid \zeta^{\prime}=1-\bar{\zeta}\right)=\pi\left(\delta^{\prime}=\right.$ $\left.\delta_{0}-\bar{\delta} \mid \zeta^{\prime}=1+\bar{\zeta}\right)$. I then have that the transition matrix of aggregate states follows from the corresponding assignment of states in (23) as

$$
\pi^{z}=\left[\begin{array}{cccc}
\pi^{\zeta} \cdot \pi^{\delta} & \pi^{\zeta} \cdot\left(1-\pi^{\delta}\right) & \left(1-\pi^{\zeta}\right) \cdot\left(1-\pi^{\delta}\right) & \left(1-\pi^{\zeta}\right) \cdot \pi^{\delta} \\
\pi^{\zeta} \cdot \pi^{\delta} & \pi^{\zeta} \cdot\left(1-\pi^{\delta}\right) & \left(1-\pi^{\zeta}\right) \cdot\left(1-\pi^{\delta}\right) & \left(1-\pi^{\zeta}\right) \cdot \pi^{\delta} \\
\left(1-\pi^{\zeta}\right) \cdot \pi^{\delta} & \left(1-\pi^{\zeta}\right) \cdot\left(1-\pi^{\delta}\right) & \pi^{\zeta} \cdot\left(1-\pi^{\delta}\right) & \pi^{\zeta} \cdot \pi^{\delta} \\
\left(1-\pi^{\zeta}\right) \cdot \pi^{\delta} & \left(1-\pi^{\zeta}\right) \cdot\left(1-\pi^{\delta}\right) & \pi^{\zeta} \cdot\left(1-\pi^{\delta}\right) & \pi^{\zeta} \cdot \pi^{\delta}
\end{array}\right]
$$

In sum, the Markov chain process of aggregate shocks is characterized by four parameters, $\left(\bar{\zeta}, \bar{\delta}, \pi^{\zeta}, \pi^{\delta}\right)$. All of these parameters are second stage parameters which I calibrate jointly to match the following targets: (i) an average variance of the cyclical component of TFP, again estimated from NIPA data, (ii) the average fluctuation of the risky return which features a standard deviation in the data of 0.16 , (iii) the autocorrelation of the cyclical component of TFP in the data and (iv) the estimated correlation of the cyclical component of TFP with risky returns.

\section{A.2 Household Problem}

To define equilibrium I adopt a de-trended version of the household model. I therefore first describe transformations of the household problem and then proceed with the equilibrium definition.

\section{A.2.1 Transformations}

Following Deaton (1991), define cash-on-hand by $X_{i, j, t}=A_{i, j, t}\left(1+r_{t}^{f}+\kappa_{i, j-1, t-1}\left(r_{t}-\right.\right.$ $\left.\left.r_{t}^{f}\right)\right)+Y_{i, j, t}$. The dynamic budget constraint then rewrites as

$$
X_{i, j+1, t+1}=\left(X_{i, j, t}-C_{i, j, t}\right)\left(1+r_{t+1}^{f}+\kappa_{i, j, t}\left(r_{t+1}-r_{t+1}^{f}\right)\right)+\mathrm{Y}_{i, j+1, t+1}
$$


I next transform the problem to de-trend the model and work with stationary variables throughout. That is, I de-trend with the deterministic trend component induced by technological progress. Along this line, define by $x_{i, j, t}=\frac{X_{i, j, t}}{\Upsilon_{t}}$ transformed cash-onhand and all other variables accordingly. Using $\omega_{t}=\frac{w_{t}}{\Upsilon_{t}}$ to denote wages per efficiency unit I have

$$
\mathrm{y}_{i, j, t}= \begin{cases}(1-\tau) \epsilon_{j} \omega_{t} \eta_{i, j, t} & \text { for } j<j r \\ b_{t} & \text { for } j \geq j r .\end{cases}
$$

Now divide the dynamic budget constraint (24) by $\Upsilon_{t}$ and rewrite to get

$$
x_{i, j+1, t+1}=\left(x_{i, j, t}-c_{i, j, t}\right) \tilde{R}_{i, j+1, t+1}+\mathrm{y}_{i, j+1, t+1} .
$$

where $\tilde{R}_{i, j+1, t+1}=\frac{\left(1+r_{t+1}^{f}+\kappa_{i, j, t}\left(r_{t+1}-r_{t+1}^{f}\right)\right)}{1+g}$.

Transform the per period utility function accordingly and take an additional monotone transformation to get

$$
u_{i, j, t}=\left[c_{i, j, t}^{\frac{1-\theta}{\gamma}}+\tilde{\beta}_{j+1}\left(\mathbb{E}_{i, j, t}\left[\left(u_{i, j+1, t+1}\right)^{1-\theta}\right]\right)^{\frac{1}{\gamma}}\right]^{\frac{\gamma}{1-\theta}}
$$

where $\tilde{\beta}_{j+1}=\beta(1+g)^{\frac{1-\theta}{\gamma}}$.

\section{A.2.2 Recursive Solution}

I iterate on the Euler equation, using ideas developed in Carroll (2006). The transformed dynamic programming problem of the household reads as

$$
u(j, \cdot)=\max _{c, \kappa}\left\{\left[c^{\frac{1-\theta}{\gamma}}+\tilde{\beta}\left(\mathbb{E}\left[u\left(j+1,(x-c) \tilde{R}^{\prime}+\mathrm{y}^{\prime}, \cdot\right)^{1-\theta}\right]\right)^{\frac{1}{\gamma}}\right]^{\frac{\gamma}{1-\theta}}\right\}
$$

where $x^{\prime}=a^{\prime} \tilde{R}^{\prime}+\mathrm{y}^{\prime}$, with $\tilde{R}^{\prime}=\frac{\left(1+r^{f^{\prime}+\kappa\left(r^{\prime}-r^{\prime}\right)}\right)}{(1+g)}$, and $\tilde{\beta}=\beta \varsigma_{j+1}((1+g))^{\frac{1-\theta}{\gamma}}$. 
The first-order conditions can be rewritten as

$$
\begin{aligned}
c: & c^{\frac{1-\theta-\gamma}{\gamma}}-\tilde{\beta}\left(\mathbb{E}\left[u(j+1, \cdot)^{1-\theta}\right]\right)^{\frac{1-\gamma}{\gamma}} \ldots \\
& \cdot \mathbb{E}\left[u(j+1, \cdot)^{\frac{(1-\theta)(\gamma-1)}{\gamma}}\left(c^{\prime}\right)^{\frac{1-\theta-\gamma}{\gamma}} \tilde{R}^{\prime}\right]=0 \\
\kappa: & \mathbb{E}\left[u(j+1, \cdot)^{\frac{(1-\theta)(\gamma-1)}{\gamma}}\left(c^{\prime}\right)^{\frac{1-\theta-\gamma}{\gamma}}\left(r^{\prime}-r^{f^{\prime}}\right)\right]=0
\end{aligned}
$$

With respect to the numerical solution, I interpolate the functions $u(j, \cdot)$ and $c(j, \cdot)$. Note that I can expect $u(j, \cdot)$ to be approximately linear, since in period $J$ it is simply given by $u(J)=c_{J}=x_{J}$.

Next, notice that $u(j+1, \cdot)$ and $c^{\prime}$ are functions of $(x-c)$ so that $c$ shows up on both sides of the equation in (28a). This would require calling a non-linear solver whenever I solve optimal consumption and portfolio shares. To alleviate this computational burden I employ the endogenous grid method of Carroll (2006). So instead of the usual exogenous grid for $x$ (and the usual endogenous grid for savings, $s=x-c$ ), the exogenous grid is $s=x-c$ and the endogenous grid is $x$. 


\section{B Additional Tables}

\section{B.1 Moments of Endogenous Variables}

Table 8: Aggregate statistics, baseline economy

\begin{tabular}{lrrrr}
\hline \hline Variable & AVG & STD & CV & AR(1) \\
\hline Capital, $K_{t}$ & $6.94 \mathrm{E}+00$ & $1.20 \mathrm{E}+00$ & $1.73 \mathrm{E}-01$ & $9.27 \mathrm{E}-01$ \\
Output, $Y_{t}$ & $2.00 \mathrm{E}+00$ & $1.26 \mathrm{E}-01$ & $6.29 \mathrm{E}-02$ & $8.72 \mathrm{E}-01$ \\
Investment $I_{t}$ & $6.25 \mathrm{E}-01$ & $5.94 \mathrm{E}-02$ & $9.50 \mathrm{E}-02$ & $1.91 \mathrm{E}-01$ \\
Excess return, $\left(r_{\sigma, t}-r_{b, t}\right)$ & $1.60 \mathrm{E}-02$ & $1.16 \mathrm{E}-01$ & $7.25 \mathrm{E}+00$ & $-5.36 \mathrm{E}-03$ \\
Stock return, $r_{\sigma, t}$ & $3.23 \mathrm{E}-02$ & $1.17 \mathrm{E}-01$ & $3.62 \mathrm{E}+00$ & $3.15 \mathrm{E}-02$ \\
Bond return, $r_{b, t}$ & $1.63 \mathrm{E}-02$ & $1.13 \mathrm{E}-02$ & $6.96 \mathrm{E}-01$ & $9.20 \mathrm{E}-01$ \\
Consumption, $C_{t}$ & $1.38 \mathrm{E}+00$ & $1.07 \mathrm{E}-01$ & $7.76 \mathrm{E}-02$ & $9.27 \mathrm{E}-01$ \\
Cons. growth, $\left(\frac{C_{t+1}}{C_{t}}-1\right)$ & $4.72 \mathrm{E}-04$ & $3.15 \mathrm{E}-02$ & $6.25 \mathrm{E}+01$ & $-3.84 \mathrm{E}-02$ \\
Wage rate, $w_{t}$ & $1.28 \mathrm{E}+00$ & $8.06 \mathrm{E}-02$ & $6.29 \mathrm{E}-02$ & $8.72 \mathrm{E}-01$ \\
TFP shocks, $z e t a$ & $1.00 \mathrm{E}+00$ & $2.00 \mathrm{E}-02$ & $2.00 \mathrm{E}-02$ & $4.38 \mathrm{E}-01$ \\
Capital-output-ratio, $\frac{K}{Y}$ & $3.44 \mathrm{E}+00$ & $3.74 \mathrm{E}-01$ & $1.09 \mathrm{E}-01$ & $9.26 \mathrm{E}-01$ \\
\hline \hline
\end{tabular}

Notes: AVG: average, STD: standard deviation, CV: coefficient of variation, AR(1): autocorrelation coef.

Table 9: Variance-covariance matrix, baseline economy

\begin{tabular}{lrrrrrr}
\hline \hline & $r_{\sigma, t}$ & $w_{t}$ & $\zeta_{t}$ & $Y_{t}$ & $I_{t}$ & $E R_{t}$ \\
\hline$r_{\sigma, t}$ & $1.37 \mathrm{E}-02$ & & & & & \\
$w_{t}$ & $-8.62 \mathrm{E}-04$ & $6.50 \mathrm{E}-03$ & & & & \\
$\zeta_{t}$ & $6.87 \mathrm{E}-05$ & $4.63 \mathrm{E}-04$ & $4.00 \mathrm{E}-04$ & & & \\
$Y_{t}$ & $-1.35 \mathrm{E}-03$ & $1.00 \mathrm{E}-02$ & $7.23 \mathrm{E}-04$ & $1.59 \mathrm{E}-02$ & & \\
$I_{t}$ & $-4.78 \mathrm{E}-03$ & $2.49 \mathrm{E}-03$ & $7.23 \mathrm{E}-04$ & $3.89 \mathrm{E}-03$ & $3.52 \mathrm{E}-03$ & \\
$C_{t}$ & $3.43 \mathrm{E}-03$ & $7.55 \mathrm{E}-03$ & $5.57 \mathrm{E}-07$ & $1.18 \mathrm{E}-02$ & $4.91 \mathrm{E}-04$ & $4.53 \mathrm{E}-03$ \\
$c_{g, t}$ & $2.53 \mathrm{E}-03$ & $-3.64 \mathrm{E}-04$ & $5.24 \mathrm{E}-05$ & $-5.69 \mathrm{E}-04$ & $-1.18 \mathrm{E}-03$ & $-2.41 \mathrm{E}-04$ \\
$\delta_{t}$ & $-8.15 \mathrm{E}-03$ & $7.61 \mathrm{E}-05$ & $2.84 \mathrm{E}-06$ & $1.19 \mathrm{E}-04$ & $2.82 \mathrm{E}-03$ & $-8.14 \mathrm{E}-03$ \\
\hline \hline
\end{tabular}

Notes: $\delta_{t}$ is the depreciation shock, $c_{g, t}=\left(\frac{C_{t+1}}{C_{t}}-1\right), E R_{t}=\left(r_{\sigma, t}-r_{b, t}\right)$, all other variables explained in table 8 . 
Table 10: Aggregate statistics, zero-borrowing (ZB) economy

\begin{tabular}{lrrrr}
\hline \hline Variable & AVG & STD & CV & AR(1) \\
\hline Capital, $K_{t}$ & $6.56 \mathrm{E}+00$ & $1.06 \mathrm{E}+00$ & $1.62 \mathrm{E}-01$ & $9.16 \mathrm{E}-01$ \\
Output, $Y_{t}$ & $1.96 \mathrm{E}+00$ & $1.17 \mathrm{E}-01$ & $5.97 \mathrm{E}-02$ & $8.57 \mathrm{E}-01$ \\
Investment $I_{t}$ & $5.91 \mathrm{E}-01$ & $5.19 \mathrm{E}-02$ & $8.79 \mathrm{E}-02$ & $1.67 \mathrm{E}-01$ \\
Excess return, $\left(r_{\sigma, t}-r_{b, t}\right)$ & $2.74 \mathrm{E}-02$ & $1.16 \mathrm{E}-01$ & $4.25 \mathrm{E}+00$ & $-5.41 \mathrm{E}-03$ \\
Stock return, $r_{\sigma, t}$ & $4.05 \mathrm{E}-02$ & $1.17 \mathrm{E}-01$ & $2.89 \mathrm{E}+00$ & $-3.37 \mathrm{E}-02$ \\
Bond return, $r_{b, t}$ & $1.32 \mathrm{E}-02$ & $1.13 \mathrm{E}-02$ & $8.62 \mathrm{E}-01$ & $9.14 \mathrm{E}-01$ \\
Consumption, $C_{t}$ & $1.37 \mathrm{E}+00$ & $1.10 \mathrm{E}-01$ & $8.00 \mathrm{E}-02$ & $9.39 \mathrm{E}-01$ \\
Cons. growth, $\left(\frac{C_{t+1}}{C_{t}}-1\right)$ & $4.21 \mathrm{E}-04$ & $3.05 \mathrm{E}-02$ & $6.59 \mathrm{E}+01$ & $1.02 \mathrm{E}-01$ \\
Wage rate, $w_{t}$ & $1.26 \mathrm{E}+00$ & $7.50 \mathrm{E}-02$ & $5.97 \mathrm{E}-02$ & $8.57 \mathrm{E}-01$ \\
TFP shocks, $z e t a$ & $1.00 \mathrm{E}+00$ & $2.00 \mathrm{E}-02$ & $2.00 \mathrm{E}-02$ & $4.38 \mathrm{E}-01$ \\
Capital-output-ratio, $\frac{K}{Y}$ & $3.32 \mathrm{E}+00$ & $3.39 \mathrm{E}-01$ & $1.02 \mathrm{E}-01$ & $9.15 \mathrm{E}-01$ \\
\hline \hline
\end{tabular}

Notes: AVG: average, STD: standard deviation, CV: coefficient of variation, AR(1): autocorrelation coefficient.

Table 11: Variance-covariance matrix, zero-borrowing (ZB) economy

\begin{tabular}{lrrrrrr}
\hline \hline & $r_{\sigma, t}$ & $w_{t}$ & $\zeta_{t}$ & $Y_{t}$ & $I_{t}$ & $E R_{t}$ \\
\hline$r_{\sigma, t}$ & $1.37 \mathrm{E}-02$ & & & & & \\
$w_{t}$ & $-7.88 \mathrm{E}-04$ & $5.62 \mathrm{E}-03$ & & & & \\
$\zeta_{t}$ & $6.88 \mathrm{E}-05$ & $4.61 \mathrm{E}-04$ & $4.00 \mathrm{E}-04$ & & & \\
$Y_{t}$ & $-1.23 \mathrm{E}-03$ & $8.55 \mathrm{E}-03$ & $7.21 \mathrm{E}-04$ & $1.37 \mathrm{E}-02$ & & \\
$I_{t}$ & $-4.22 \mathrm{E}-03$ & $1.35 \mathrm{E}-03$ & $6.30 \mathrm{E}-04$ & $2.10 \mathrm{E}-03$ & $2.69 \mathrm{E}-03$ & \\
$C_{t}$ & $2.98 \mathrm{E}-03$ & $7.21 \mathrm{E}-03$ & $9.11 \mathrm{E}-05$ & $1.13 \mathrm{E}-02$ & $-3.63 \mathrm{E}-04$ & $4.11 \mathrm{E}-03$ \\
$c_{g, t}$ & $2.53 \mathrm{E}-03$ & $-1.83 \mathrm{E}-04$ & $9.34 \mathrm{E}-05$ & $-2.86 \mathrm{E}-04$ & $-8.42 \mathrm{E}-04$ & $2.85 \mathrm{E}-04$ \\
$\delta_{t}$ & $-8.15 \mathrm{E}-03$ & $9.04 \mathrm{E}-05$ & $3.45 \mathrm{E}-06$ & $1.41 \mathrm{E}-04$ & $2.55 \mathrm{E}-03$ & $-8.14 \mathrm{E}-03$ \\
\hline \hline
\end{tabular}

Notes: $\delta_{t}$ is the depreciation shock, $c_{g, t}=\left(\frac{C_{t+1}}{C_{t}}-1\right), E R_{t}=\left(r_{\sigma, t}-r_{b, t}\right)$, all other variables explained in table 10 . 
Table 12: Aggregate statistics, idiosyncratic risk (IR) economy

\begin{tabular}{lrrrr}
\hline \hline Variable & AVG & STD & CV & AR(1) \\
\hline Capital, $K_{t}$ & $6.58 \mathrm{E}+00$ & $9.92 \mathrm{E}-01$ & $1.51 \mathrm{E}-01$ & $9.08 \mathrm{E}-01$ \\
Output, $Y_{t}$ & $1.97 \mathrm{E}+00$ & $1.11 \mathrm{E}-01$ & $5.63 \mathrm{E}-02$ & $8.43 \mathrm{E}-01$ \\
Investment $I_{t}$ & $5.92 \mathrm{E}-01$ & $5.91 \mathrm{E}-02$ & $9.97 \mathrm{E}-02$ & $1.39 \mathrm{E}-01$ \\
Excess return, $\left(r_{\sigma, t}-r_{b, t}\right)$ & $2.36 \mathrm{E}-02$ & $1.16 \mathrm{E}-01$ & $4.93 \mathrm{E}+00$ & $-4.75 \mathrm{E}-03$ \\
Stock return, $r_{\sigma, t}$ & $3.86 \mathrm{E}-02$ & $1.17 \mathrm{E}-01$ & $3.03 \mathrm{E}+00$ & $-3.36 \mathrm{E}-02$ \\
Bond return, $r_{b, t}$ & $1.51 \mathrm{E}-02$ & $1.05 \mathrm{E}-02$ & $7.00 \mathrm{E}-01$ & $9.02 \mathrm{E}-01$ \\
Consumption, $C_{t}$ & $1.37 \mathrm{E}+00$ & $1.14 \mathrm{E}-01$ & $8.32 \mathrm{E}-02$ & $9.10 \mathrm{E}-01$ \\
Cons. growth, $\left(\frac{C_{t+1}}{C_{t}}-1\right)$ & $6.54 \mathrm{E}-04$ & $3.52 \mathrm{E}-02$ & $5.37 \mathrm{E}+01$ & $-4.66 \mathrm{E}-02$ \\
Wage rate, $w_{t}$ & $1.26 \mathrm{E}+00$ & $7.08 \mathrm{E}-02$ & $5.63 \mathrm{E}-02$ & $8.43 \mathrm{E}-01$ \\
TFP shocks, $z e t a$ & $1.00 \mathrm{E}+00$ & $2.00 \mathrm{E}-02$ & $2.00 \mathrm{E}-02$ & $4.38 \mathrm{E}-01$ \\
Capital-output-ratio, $\frac{K}{Y}$ & $3.33 \mathrm{E}+00$ & $3.18 \mathrm{E}-01$ & $9.54 \mathrm{E}-02$ & $9.07 \mathrm{E}-01$ \\
\hline \hline
\end{tabular}

Notes: AVG: average, STD: standard deviation, CV: coefficient of variation, AR(1): autocorrelation coefficient.

Table 13: Variance-covariance matrix, idiosyncratic risk (IR) economy

\begin{tabular}{lrrrrrr}
\hline \hline & $r_{\sigma, t}$ & $w_{t}$ & $\zeta_{t}$ & $Y_{t}$ & $I_{t}$ & $E R_{t}$ \\
\hline$r_{\sigma, t}$ & $1.37 \mathrm{E}-02$ & & & & & \\
$w_{t}$ & $-6.85 \mathrm{E}-04$ & $5.02 \mathrm{E}-03$ & & & & \\
$\zeta_{t}$ & $6.93 \mathrm{E}-05$ & $4.70 \mathrm{E}-04$ & $4.00 \mathrm{E}-04$ & & & \\
$Y_{t}$ & $-1.07 \mathrm{E}-03$ & $7.84 \mathrm{E}-03$ & $7.34 \mathrm{E}-04$ & $1.23 \mathrm{E}-02$ & & \\
$I_{t}$ & $-5.37 \mathrm{E}-03$ & $8.57 \mathrm{E}-04$ & $6.98 \mathrm{E}-04$ & $1.34 \mathrm{E}-03$ & $3.49 \mathrm{E}-03$ & \\
$C_{t}$ & $4.30 \mathrm{E}-03$ & $6.99 \mathrm{E}-03$ & $3.61 \mathrm{E}-05$ & $1.09 \mathrm{E}-02$ & $-2.15 \mathrm{E}-03$ & $5.38 \mathrm{E}-03$ \\
$c_{g, t}$ & $3.07 \mathrm{E}-03$ & $-4.16 \mathrm{E}-04$ & $6.85 \mathrm{E}-05$ & $-6.49 \mathrm{E}-04$ & $-1.50 \mathrm{E}-03$ & $-3.52 \mathrm{E}-04$ \\
$\delta_{t}$ & $-8.15 \mathrm{E}-03$ & $7.25 \mathrm{E}-05$ & $2.52 \mathrm{E}-06$ & $1.13 \mathrm{E}-04$ & $3.30 \mathrm{E}-03$ & $-8.14 \mathrm{E}-03$ \\
\hline \hline
\end{tabular}

Notes: $\delta_{t}$ is the depreciation shock, $c_{g, t}=\left(\frac{C_{t+1}}{C_{t}}-1\right), E R_{t}=\left(r_{\sigma, t}-r_{b, t}\right)$, all other variables explained in table 12 . 
Table 14: Aggregate statistics, zero-borrowing and idiosyncratic risk (ZB,IR)

\begin{tabular}{lrrrr}
\hline \hline Variable & AVG & STD & CV & AR(1) \\
\hline Capital, $K_{t}$ & $6.67 \mathrm{E}+00$ & $9.86 \mathrm{E}-01$ & $1.48 \mathrm{E}-01$ & $9.05 \mathrm{E}-01$ \\
Output, $Y_{t}$ & $1.98 \mathrm{E}+00$ & $1.09 \mathrm{E}-01$ & $5.54 \mathrm{E}-02$ & $8.38 \mathrm{E}-01$ \\
Investment $I_{t}$ & $6.00 \mathrm{E}-01$ & $6.02 \mathrm{E}-02$ & $1.00 \mathrm{E}-01$ & $1.49 \mathrm{E}-01$ \\
Excess return, $\left(r_{\sigma, t}-r_{b, t}\right)$ & $2.74 \mathrm{E}-02$ & $1.16 \mathrm{E}-01$ & $4.24 \mathrm{E}+00$ & $-5.07 \mathrm{E}-03$ \\
Stock return, $r_{\sigma, t}$ & $3.91 \mathrm{E}-02$ & $1.17 \mathrm{E}-01$ & $2.99 \mathrm{E}+00$ & $-3.37 \mathrm{E}-02$ \\
Bond return, $r_{b, t}$ & $1.17 \mathrm{E}-02$ & $1.03 \mathrm{E}-02$ & $8.74 \mathrm{E}-01$ & $9.00 \mathrm{E}-01$ \\
Consumption, $C_{t}$ & $1.38 \mathrm{E}+00$ & $1.17 \mathrm{E}-01$ & $8.48 \mathrm{E}-02$ & $9.06 \mathrm{E}-01$ \\
Cons. growth, $\left(\frac{C_{t+1}}{C_{t}}-1\right)$ & $7.07 \mathrm{E}-04$ & $3.66 \mathrm{E}-02$ & $5.18 \mathrm{E}+01$ & $-4.69 \mathrm{E}-02$ \\
Wage rate, $w_{t}$ & $1.26 \mathrm{E}+00$ & $7.00 \mathrm{E}-02$ & $5.54 \mathrm{E}-02$ & $8.38 \mathrm{E}-01$ \\
TFP shocks, $z e t a$ & $1.00 \mathrm{E}+00$ & $2.00 \mathrm{E}-02$ & $2.00 \mathrm{E}-02$ & $4.38 \mathrm{E}-01$ \\
Capital-output-ratio, $\frac{K}{Y}$ & $3.36 \mathrm{E}+00$ & $3.14 \mathrm{E}-01$ & $9.35 \mathrm{E}-02$ & $9.04 \mathrm{E}-01$ \\
\hline \hline
\end{tabular}

Notes: AVG: average, STD: standard deviation, CV: coefficient of variation, AR(1): autocorrelation coefficient.

Table 15: Variance-covariance matrix, zero-borrowing and idiosyncratic risk

\begin{tabular}{lrrrrrr}
\hline \hline & $r_{\sigma, t}$ & $w_{t}$ & $\zeta_{t}$ & $Y_{t}$ & $I_{t}$ & $E R_{t}$ \\
\hline$r_{\sigma, t}$ & $1.37 \mathrm{E}-02$ & & & & & \\
$w_{t}$ & $-6.58 \mathrm{E}-04$ & $4.91 \mathrm{E}-03$ & & & & \\
$\zeta_{t}$ & $6.85 \mathrm{E}-05$ & $4.73 \mathrm{E}-04$ & $4.00 \mathrm{E}-04$ & & & \\
$Y_{t}$ & $-1.03 \mathrm{E}-03$ & $7.66 \mathrm{E}-03$ & $7.39 \mathrm{E}-04$ & $1.20 \mathrm{E}-02$ & & \\
$I_{t}$ & $-5.56 \mathrm{E}-03$ & $6.44 \mathrm{E}-04$ & $6.82 \mathrm{E}-04$ & $1.01 \mathrm{E}-03$ & $3.62 \mathrm{E}-03$ & \\
$C_{t}$ & $4.53 \mathrm{E}-03$ & $7.02 \mathrm{E}-03$ & $5.70 \mathrm{E}-05$ & $1.10 \mathrm{E}-02$ & $-2.62 \mathrm{E}-03$ & $5.60 \mathrm{E}-03$ \\
$c_{g, t}$ & $3.23 \mathrm{E}-03$ & $-4.27 \mathrm{E}-04$ & $7.89 \mathrm{E}-05$ & $-6.67 \mathrm{E}-04$ & $-1.60 \mathrm{E}-03$ & $-3.74 \mathrm{E}-04$ \\
$\delta_{t}$ & $-8.15 \mathrm{E}-03$ & $7.14 \mathrm{E}-05$ & $2.52 \mathrm{E}-06$ & $1.12 \mathrm{E}-04$ & $3.43 \mathrm{E}-03$ & $-8.14 \mathrm{E}-03$ \\
\hline \hline
\end{tabular}

Notes: $\delta_{t}$ is the depreciation shock, $c_{g, t}=\left(\frac{C_{t+1}}{C_{t}}-1\right), E R_{t}=\left(r_{\sigma, t}-r_{b, t}\right)$, all other variables explained in table 14 . 


\section{B.2 Estimates of the Approximate Law of Motion}

Table 16: Coefficients of law of motion, baseline economy

\begin{tabular}{rrrrr}
\hline \hline \multicolumn{5}{c}{ Dependent variable: $\log \left(K^{\prime}\right)$} \\
\hline$z$ & constant & $\log (K)$ & $\log (K)^{2}$ & $R^{2}$ \\
\hline 1 & $1.86 \mathrm{E}-01$ & $8.10 \mathrm{E}-01$ & $2.97 \mathrm{E}-02$ & 0.9999 \\
2 & $2.37 \mathrm{E}-01$ & $8.76 \mathrm{E}-01$ & $1.59 \mathrm{E}-02$ & 1.0000 \\
3 & $1.84 \mathrm{E}-01$ & $8.30 \mathrm{E}-01$ & $2.31 \mathrm{E}-02$ & 1.0000 \\
4 & $2.47 \mathrm{E}-01$ & $8.82 \mathrm{E}-01$ & $1.31 \mathrm{E}-02$ & 1.0000 \\
\hline \multicolumn{5}{c}{ Dependent variable: $\mu^{\prime}$} \\
\hline$z^{\prime}$ & constant & $\log \left(K^{\prime}\right)$ & $\log \left(K^{\prime}\right)^{2}$ & $R^{2}$ \\
\hline 1 & $1.28 \mathrm{E}-02$ & $1.61 \mathrm{E}-04$ & $6.60 \mathrm{E}-04$ & 0.9965 \\
2 & $1.34 \mathrm{E}-02$ & $-2.87 \mathrm{E}-04$ & $8.24 \mathrm{E}-04$ & 0.9970 \\
3 & $1.26 \mathrm{E}-02$ & $3.05 \mathrm{E}-04$ & $6.21 \mathrm{E}-04$ & 0.9969 \\
4 & $1.39 \mathrm{E}-02$ & $-8.62 \mathrm{E}-04$ & $9.74 \mathrm{E}-04$ & 0.9963 \\
\hline \hline
\end{tabular}

Table 17: Coefficients of laws of motion, zero-borrowing (ZB) economy

\begin{tabular}{rrrrr}
\hline \hline \multicolumn{5}{c}{ Dependent variable: $\log \left(K^{\prime}\right)$} \\
\hline$z$ & constant & $\log (K)$ & $\log (K)^{2}$ & $R^{2}$ \\
\hline 1 & $2.02 \mathrm{E}-01$ & $7.95 \mathrm{E}-01$ & $3.20 \mathrm{E}-02$ & 0.9998 \\
2 & $2.43 \mathrm{E}-01$ & $8.75 \mathrm{E}-01$ & $1.39 \mathrm{E}-02$ & 0.9999 \\
3 & $2.41 \mathrm{E}-01$ & $7.68 \mathrm{E}-01$ & $3.78 \mathrm{E}-02$ & 0.9998 \\
4 & $2.25 \mathrm{E}-01$ & $9.11 \mathrm{E}-01$ & $2.98 \mathrm{E}-03$ & 0.9998 \\
\hline \multicolumn{5}{c}{ Dependent variable: $\mu^{\prime}$} \\
\hline$z^{\prime}$ & constant & $\log \left(K^{\prime}\right)$ & $\log \left(K^{\prime}\right)^{2}$ & $R^{2}$ \\
\hline 1 & $4.29 \mathrm{E}-02$ & $-2.15 \mathrm{E}-02$ & $6.90 \mathrm{E}-03$ & 0.9127 \\
2 & $4.44 \mathrm{E}-02$ & $-2.45 \mathrm{E}-02$ & $8.19 \mathrm{E}-03$ & 0.9028 \\
3 & $3.90 \mathrm{E}-02$ & $-1.79 \mathrm{E}-02$ & $6.06 \mathrm{E}-03$ & 0.9117 \\
4 & $4.46 \mathrm{E}-02$ & $-2.53 \mathrm{E}-02$ & $8.45 \mathrm{E}-03$ & 0.8939 \\
\hline \hline
\end{tabular}


Table 18: Coefficients of law of motion, idiosyncratic risk (IR) economy

\begin{tabular}{rrrrr}
\hline \hline \multicolumn{5}{c}{ Dependent variable: $\log \left(K^{\prime}\right)$} \\
\hline$z$ & constant & $\log (K)$ & $\log (K)^{2}$ & $R^{2}$ \\
\hline 1 & $1.95 \mathrm{E}-01$ & $8.12 \mathrm{E}-01$ & $2.49 \mathrm{E}-02$ & 1.0000 \\
2 & $2.82 \mathrm{E}-01$ & $8.39 \mathrm{E}-01$ & $2.19 \mathrm{E}-02$ & 1.0000 \\
3 & $2.24 \mathrm{E}-01$ & $8.00 \mathrm{E}-01$ & $2.68 \mathrm{E}-02$ & 1.0000 \\
4 & $3.06 \mathrm{E}-01$ & $8.29 \mathrm{E}-01$ & $2.32 \mathrm{E}-02$ & 1.0000 \\
\hline \multicolumn{5}{c}{ Dependent variable: $\mu^{\prime}$} \\
\hline$z^{\prime}$ & constant & $\log \left(K^{\prime}\right)$ & $\log \left(K^{\prime}\right)^{2}$ & $R^{2}$ \\
\hline 1 & $1.73 \mathrm{E}-02$ & $1.66 \mathrm{E}-03$ & $7.69 \mathrm{E}-04$ & 0.9981 \\
2 & $1.82 \mathrm{E}-02$ & $9.64 \mathrm{E}-04$ & $1.03 \mathrm{E}-03$ & 0.9983 \\
3 & $1.71 \mathrm{E}-02$ & $1.66 \mathrm{E}-03$ & $7.81 \mathrm{E}-04$ & 0.9980 \\
4 & $1.88 \mathrm{E}-02$ & $1.33 \mathrm{E}-04$ & $1.25 \mathrm{E}-03$ & 0.9981 \\
\hline \hline
\end{tabular}

Table 19: Coefficients of law of motion, zero-borrowing and idiosyncratic risk

\begin{tabular}{ccccr}
\hline \hline \multicolumn{5}{c}{ Dependent variable: $\log \left(K^{\prime}\right)$} \\
\hline$z$ & constant & $\log (K)$ & $\log (K)^{2}$ & $R^{2}$ \\
\hline 1 & $2.09 \mathrm{E}-01$ & $8.04 \mathrm{E}-01$ & $2.61 \mathrm{E}-02$ & 1.0000 \\
2 & $2.93 \mathrm{E}-01$ & $8.31 \mathrm{E}-01$ & $2.28 \mathrm{E}-02$ & 1.0000 \\
3 & $2.36 \mathrm{E}-01$ & $7.92 \mathrm{E}-01$ & $2.79 \mathrm{E}-02$ & 1.0000 \\
4 & $3.16 \mathrm{E}-01$ & $8.22 \mathrm{E}-01$ & $2.41 \mathrm{E}-02$ & 1.0000 \\
\hline \multicolumn{5}{c}{ Dependent variable: $\mu^{\prime}$} \\
\hline$z^{\prime}$ & constant & $\log \left(K^{\prime}\right)$ & $\log \left(K^{\prime}\right)^{2}$ & $R^{2}$ \\
\hline 1 & $2.21 \mathrm{E}-02$ & $4.90 \mathrm{E}-04$ & $1.10 \mathrm{E}-03$ & 0.9587 \\
2 & $2.30 \mathrm{E}-02$ & $-2.90 \mathrm{E}-04$ & $1.38 \mathrm{E}-03$ & 0.9708 \\
3 & $2.07 \mathrm{E}-02$ & $1.70 \mathrm{E}-03$ & $8.08 \mathrm{E}-04$ & 0.9576 \\
4 & $2.33 \mathrm{E}-02$ & $-7.76 \mathrm{E}-04$ & $1.51 \mathrm{E}-03$ & 0.9694 \\
\hline \hline
\end{tabular}




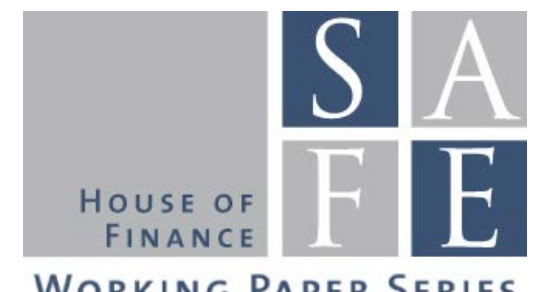

WORKING PAPER SERIES

\section{Recent Issues}

No. 228 Roberto C. Panzica

No. 227 Mila Getmansky, Ravi

Jagannathan, Loriana Pelizzon, Ernst Schaumburg, Darya Yuferova

No. 226 Loriana Pelizzon, Marti G. Subrahmanyam, Davide Tomio, Jun Uno

No. 225 Monica Billio, Massimiliano Caporin, Lorenzo Frattarolo, Loriana Pelizzon

No. 224 Giulio Girardi, Kathleen W. Hanley, Stanislava Nikolova, Loriana Pelizzon, Mila Getmansky Sherman

No. 223 Florian Deuflhard

No. 222 Vanessa Endrejat, Matthias Thiemann

No. 221 Axel H. Börsch-Supan, Klaus Härtl, Duarte N. Leite, Alexander Ludwig

No. 220 Yangming Bao, Martin R. Goetz

No. 219 Andreas Hackethal - Christine Laudenbach - Steffen Meyer Annika Weber

No. 218 Florian Hoffmann, Roman Inderst, Marcus Opp

No. 217 Maddalena Davoli, Jia Hou

No. 216
Stefano Colonnello, Giuliano Curatola, Alessandro Gioffré
Idiosyncratic Volatility Puzzle: The Role of Assets' Interconnections

Stock Price Crashes: Role of Slow-Moving Capital

Central Bank-Driven Mispricing?

Networks in risk spillovers:

A multivariate GARCH perspective

Portfolio Similarity and Asset Liquidation in the Insurance Industry

Quantifying Inertia in Retail Deposit Markets

Reviving the Shadow Banking Chain in Europe: Regulatory Agency, Technical Complexity and the Dynamics of CoHabitation

Endogenous Retirement Behavior of Heterogeneous Households Under Pension Reforms

Local Peer Effects and Corporate Investment

Client Involvement in Expert Advice Antibiotics in Finance?

Only Time will Tell: A Theory of Deferred Compensation

Financial Literacy and Socialist Education: Lessons from the German Reunification

Pricing Sin Stocks: Ethical Preference vs. Risk Aversion 